

University of Pennsylvania

ScholarlyCommons

Management Papers

Wharton Faculty Research

\title{
$2-2017$
}

\section{In With the Big, Out With the Small: Removing Small-Scale Reservations in India}

Leslie A. Martin

The University of Melbourne

Shanthi Nataraj

Ann E. Harrison

University of Pennsylvania

Follow this and additional works at: https://repository.upenn.edu/mgmt_papers

Part of the Management Sciences and Quantitative Methods Commons

\section{Recommended Citation}

Martin, L. A., Nataraj, S., \& Harrison, A. E. (2017). In With the Big, Out With the Small: Removing SmallScale Reservations in India. American Economic Review, 107 (2), 354-386. http://dx.doi.org/10.1257/ aer.20141335

This paper is posted at ScholarlyCommons. https://repository.upenn.edu/mgmt_papers/230

For more information, please contact repository@pobox.upenn.edu. 


\title{
In With the Big, Out With the Small: Removing Small-Scale Reservations in India
}

\author{
Abstract \\ An ongoing debate in employment policy is whether promoting small and medium enterprises creates \\ jobs. We use the elimination of small-scale industry (SSI) promotion in India to address this question. For \\ 60 years, SSI promotion in India focused on reserving certain products for manufacture by small and \\ medium enterprises. We identify the consequences for employment growth, investment, output, \\ productivity, and wages of dismantling India's SSI reservations. We exploit variation in the timing of de- \\ reservation across products and also measure the long-run impact of national SSI policy changes using \\ variation in pretreatment exposure at the district level. Districts more exposed to de-reservation \\ experienced higher employment and output growth. Entrants into the de-reserved product spaces and \\ incumbents that were previously constrained by the size restrictions drove the increase in growth. The \\ results suggest that dismantling India's SSI policies encouraged overall employment growth. \\ Disciplines \\ Management Sciences and Quantitative Methods
}




\title{
In with the Big, Out with the Small: Removing Small-Scale Reservations in India
}

\author{
By Leslie A. Martin, Shanthi Nataraj, And Ann E. Harrison*
}

An ongoing debate in employment policy is whether promoting small and medium enterprises creates jobs. We use the elimination of small-scale industry (SSI) promotion in India to address this question. For 60 years, SSI promotion in India focused on reserving certain products for manufacture by small and medium enterprises. We identify the consequences for employment growth, investment, output, productivity, and wages of dismantling India's SSI reservations. We exploit variation in the timing of de-reservation across products and also measure the long-run impact of national SSI policy changes using variation in pretreatment exposure at the district level. Districts more exposed to de-reservation experienced higher employment and output growth. Entrants into the de-reserved product spaces and incumbents that were previously constrained by the size restrictions drove the increase in growth. The results suggest that dismantling India's SSI policies encouraged overall employment growth. (JEL E24, L25, L53, L60, O14, O25)

Most governments promote small and medium enterprises (SME). Why? The US Trade Representative's office suggests that "America's small businesses are the backbone of the US economy." "1] The United States Small Business Jobs Act, signed into law in 2010, provides a range of credit opportunities and tax cuts to promote small and medium enterprises. In Europe, the 2008 Small Business Act for Europe seeks to reduce regulatory burdens for small businesses, provides tax incentives

\footnotetext{
* Martin: University of Melbourne, 111 Barry Street, University of Melbourne, VIC 3010 Australia (e-mail: leslie.martin@unimelb.edu.au); Nataraj: RAND Corporation, 1776 Main Street, Santa Monica, CA 90401 (e-mail: snataraj@rand.org); Harrison: The Wharton School, University of Pennsylvania, 3620 Locust Walk, Philadelphia, PA 19104, and NBER (e-mail: annh@wharton.upenn.edu). We thank Mr. M. L. Philip, Mr. P. C. Nirala, Dr. Praveen Shukla, and Mr. M. M. Hasija at the Ministry of Statistics and Programme Implementation for their assistance in obtaining and interpreting the ASI data, and David Nelson and Steve Otto for assisting in matching the product reservation codes with the ASICC codes. We are grateful to Richard Freeman, David Neumark, and Jeff Wenger, as well as seminar participants at the 2016 ASSA Annual Meeting, Harvard, the London School of Economics, RAND, and the Wharton International Lunch for their valuable comments. We are also grateful to the three referees for their very helpful suggestions, which greatly improved the paper. This material is based upon work supported by the National Science Foundation under grant no. SES-0922332. Any opinions, findings, and conclusions or recommendations expressed in this material are those of the authors and do not necessarily reflect the views of the National Science Foundation. Leslie Martin and Ann Harrison declare that they have no relevant or material financial interests that relate to the research described in this paper. Shanthi Nataraj has received funding for other research projects from the World Bank and the UK Department for International Development.

Go to https://doi.org/10.1257/aer.20141335 to visit the article page for additional materials and author disclosure statement(s).

${ }^{1}$ https://ustr.gov/uscolombiatpa/small_business (accessed August 7, 2015).
} 
such as value added tax (VAT) reductions, and promotes access to financing. SME promotion is also an important priority in Asia. In 2002, China passed the SME promotion law, which designated a central budget for promotion of small and medium enterprises across a variety of areas including credit provision, technological innovation, exporting, environmental protection, and worker training. India, the focus of our study, has had extensive regulations in place to promote small and medium enterprises, based in part on its socialist legacy.

Much of the support for SMEs stems from the assumption that SMEs do a better job of promoting aggregate job creation. Yet the evidence to date on firm size and employment growth is inconclusive. For developing countries, a number of studies document that small firms grow faster than large firms (Mead and Liedholm 1998; Gunning and Mengistae 2001; Sleuwaegen and Goedhuys 2002; Bigsten and Gebreeyesus 2007; Ayyagari, Demirguc-Kunt, and Maksimovic 2011). In contrast, van Biesebroeck (2005) shows that after controlling for a number of other characteristics, medium and large firms in nine sub-Saharan African countries grow faster than small firms. In developed countries, a number of early studies found that small firms grow more quickly (see, among others, Evans 1987a, b; Hall 1987; and Sutton 1997). Neumark, Wall, and Zhang (2011) find evidence that small businesses create more jobs. However, they show that the negative relationship between firm size and job creation is sensitive to whether size is measured using base period size or average size of the enterprise. In particular, because of the possibility of mean reversion, estimates using average firm size show smaller but still significantly higher job creation rates for smaller firms.

Haltiwanger, Jarmin, and Miranda (2013) argue that earlier papers on US firms are flawed due to measurement issues and omitted variable bias. They present evidence showing that the higher employment growth of smaller enterprises disappears once they control for age. Haltiwanger Jarmin, and Miranda (2013) suggest that policymakers seeking to promote small businesses should also consider the effects of firm age. For US data, the evidence suggests both that younger firms grow faster than older firms, and that larger firms grow faster than smaller firms after conditioning on age.

One reason why it is so difficult to estimate both the effects of SME promotion as well as the job creation benefits of small firms is that firm size is not randomly assigned. In this paper, we use the elimination of a widespread policy to promote small-scale enterprises to evaluate the effects of SME promotion on employment outcomes. India's promotion of small and medium enterprises targeted products, not firms, and after decades of support was rapidly eliminated starting in 1997. We use the elimination of the program, which covered one-quarter of all formal sector establishments prior to the reform, to measure the employment, productivity, and wage effects of a reversal of SME promotion.

India is an ideal country to study SME promotion. For the past 60 years, India has attempted to boost employment growth by shielding small manufacturing establishments from competition. Promotion measures have included the types of policies used all over the world: subsidized credit, technical assistance, excise tax exemptions, preference in government procurement, and subsidies for power and capital. Until 1997, the premier instrument for protecting small establishments in India was its policy of reserving a number of products for exclusive production by small-scale industry. Proponents of small establishment promotion argued that these policies 
encouraged labor-intensive growth, mitigated capital market imperfections, and shifted income toward lower wage earners (Hussain 1997).

Critics of SME promotion in India argued that these policies in fact discouraged firm growth and slowed the overall expansion of the manufacturing sector. Mohan (2002) argues that small establishments making reserved products were discouraged from growing or upgrading their technology, because they would have had to stop making those products if their investment grew above the allowed limits for small-scale industry (SSI). Panagariya (2008) hypothesizes that the policy of reserving many labor-intensive products for SSIs limited Indian exports of these products.

In this paper, we address whether SME promotion through product reservation is an effective way of promoting job creation. India's dismantling of small-scale reservations - which were specifically geared toward promoting small establishmentsallows us to address the linkages between establishment size and job growth. We focus on the peak period for dismantling SSI reservations (2000 to 2007) to identify the impact on the growth of employment, output, investment, and wages. We use a newly available panel dataset from India's Annual Survey of Industries (ASI). While these data were previously available as a repeated cross section, the new dataset provides unique establishment identifiers, allowing us to bypass the tricky business of trying to link establishments through beginning and end of year accounting information. We also explore the net impact of de-reservation at the product and district levels. The panel dataset does not include district identifiers; however, we have created the first mapping of the panel dataset to district locations by merging these to annual cross sections with district information which we purchased separately. ${ }^{2}$

We classify establishments as incumbents (those producing the reserved product prior to the reforms) or entrants (those that moved into the product space after the product was de-reserved). We find that when products were removed from the reserved list, overall employment, investment, and output grew. This growth was driven by entrants and by incumbents that were previously constrained by the capital limits. In contrast, smaller incumbents shrank.

What was the net effect of the de-reservation on employment? To address this question, we explore the net impact of de-reservation at the district level, exploiting the fact that SSI policies were set nationally but their effects varied locally depending on prior exposure. At the district level, the elimination of SSI policies was an exogenous shock whose severity was greatest in regions whose preexisting production structure included a large share of reserved products. We link our establishment-level data to the districts in which the establishments operate. We then compare changes in employment, output, investment, and wage outcomes for districts that were more or less exposed to the de-reservation based on their preexisting product mix. We find that districts that were more exposed to the de-reservation based on their preexisting product mix experienced higher employment and output growth over the period from 2000 to 2007 . The results suggest that the average change in the fraction of de-reserved employment $(0.076)$ is associated with a 6 percent increase in district-level employment.

\footnotetext{
${ }^{2}$ Information on purchasing the ASI data can be found at http://mospi.nic.in/Mospi_New/site/inner. aspx ?status $=3 \&$ menu_id=73.
} 
The de-reservation may also have affected informal (unorganized) manufacturing employment. ${ }^{3}$ If de-reservation simply pushed some workers into informality, then this would be a negative outcome that our ASI data would miss. To investigate this possibility, we conduct a similar, district-level analysis using unorganized manufacturing surveys from 2000 and 2005. We find no statistically significant association between the fraction of de-reservation and district-level employment in unorganized manufacturing. If anything, the evidence suggests that de-reservation may be associated with workers shifting from the unorganized to the organized (formal) sector.

We are fortunate that most of India's other major reforms, including delicensing and major trade reform episodes, were completed before the period of our analysis. However, another important consideration is the potential endogeneity of the reforms. As an illustration, Chari and Gupta (2008), focusing on foreign direct investment (FDI) liberalization, show that India's 1991 FDI liberalization was less likely in more concentrated sectors and sectors with a high share of state-owned enterprises. We address potential endogeneity of the SSI reforms by controlling for product-level, event-time trends in the years leading up to de-reservation, and by documenting that there are no pretreatment trends before products were de-reserved. We also conduct a placebo test and find that the effect of the true de-reservation remains robust, while the placebos show no effect.

Some might argue that India's promotion of small firms could have been better designed. Perhaps a more sensible policy might have been more successful at promoting employment for small-scale businesses in India. Many countries promote small firms by facilitating access to credit; others provide worker training and tax relief. If large companies naturally generate higher employment growth, then such SME policies may not be optimal. Furthermore, these narrowly targeted policies impose additional costs that increase with establishment size, which ultimately discourages growth. At the end of the paper, we also explore whether large Indian enterprises not affected by SME promotion had faster employment growth than smaller enterprises also outside the SME laws. Our results, which demonstrate a strong link between larger establishment size and employment growth, suggest caution in using SME promotion as a vehicle for job creation.

Others who have studied firm growth in India include Das (1995) and Shanmugam and Bhaduri (2002). Both studies document that small firms grow more quickly; however, these analyses are limited to small, specialized subsets of Indian manufacturing and do not shed light on why overall employment growth in labor-intensive industries has been slow. More recently, Garcia-Santana and Pijoan-Mas (2014) calibrate a span-of-control model that accounts for the reservation policy, using data from 2001, when most reservations were still in place. They simulate the effects of removing the reservation policy and predict that doing so would increase manufacturing output per worker by nearly 7 percent. To our knowledge, ours is the first paper to empirically test the results of the actual dismantling of the SSI reservations policy at the establishment level, which makes it quite complementary to Garcia-Santana and Pijoan-Mas. Our finding that the average decline in reservations would increase employment by approximately 6 percent at the district level is

\footnotetext{
${ }^{3}$ India uses the terms unorganized and informal to mean slightly different things. Our data cover the unorganized sector, although we use the two terms interchangeably.
} 
remarkably close to the simulation results for output generated by their structural model. However, our primary focus is on generating employment, not output. More broadly, this paper contributes to the literature examining why so much employment in developing countries is found in small firms (La Porta and Shleifer 2008, 2014; McCaig and Pavcnik 2015; Tybout 2000, 2014; among others).

While this paper focuses primarily on the linkages between establishment size and employment growth, there is also a related literature on policy distortions, productivity growth, and reallocation of production in developing countries. This includes Aghion et al. (2008); Alfaro and Chari (2009, 2014); Banerjee (2006); Besley and Burgess (2004); Goldberg et al. (2010a, b); Hsieh and Olken (2014); McCaig and Pavcnik (2014); and Nataraj (2011). Aghion et al. (2008) and Besley and Burgess (2004) are both important early papers on the costs of regulation in India that show how licensing and labor market regulations had significant but heterogeneous costs for both growth and productivity. Besley and Burgess (2004) emphasize the movement to informal sector enterprises as a result of regulation, an issue which we address at the end of this paper using data on unorganized manufacturing.

In India, Alfaro and Chari $(2009,2014)$ examine more broadly changes in market structure and firm behavior over a longer time period spanning before and after the 1991 reforms. Alfaro and Chari (2009) find that firms which dominated in the early years continue to dominate in later decades, with the exception of the services sector where there is more significant dynamism. Despite significant entry by new firms, Alfaro and Chari show (using the Prowess data of all publicly listed firms) continued dominance of state-owned enterprises and older manufacturing enterprises..$^{4}$

Goldberg et al. (2010a) are the first authors to use product-level data for India. They explore the determinants of new product introductions as a function of the earlier trade reforms, which were largely completed by the time the SSI liberalization occurred. Goldberg et al. (2010a) find that falling input tariffs account for more than 30 percent of new product introductions during their sample period. Goldberg et al. (2010b) examine whether the rationalization of product lines is linked to India's trade reforms, and find very weak links between the two. Our paper has a different, but complementary focus: we are interested in how the elimination of product restrictions that favored small establishments affected employment growth.

Our findings are also consistent with a growing theoretical literature on heterogeneous firms and productivity (Melitz 2003). Many of these papers show that reforms that reallocate production away from less efficient and toward more efficient firms are associated with significant productivity increases. Conversely, Garicano, LeLarge, and Van Reenen (2016) show that countries like France which retain size-contingent labor regulations constrain firms from reaching optimal size (and consequently optimal productivity) levels. Aghion et al. (2008) develop a model in the working paper version of their article where the dismantling of the License Raj encourages firm entry and expansion among more productive firms, as well as exit and contraction among less productive firms, with more pronounced effects in

\footnotetext{
${ }^{4}$ Alfaro and Chari also examine the impact of the 1991 reforms on the overall size distribution of firms, finding that the reforms led to the entry of many small firms and reinforced the role of larger firms. Our paper is complementary to theirs, as we focus specifically on the removal of SSI policies, a reform that occurred after the major trade reforms and delicensing of earlier years.
} 
regions with lower labor costs. The net effect is a reallocation of economic activity toward pro-employer states.

In our context, the de-reservation policy may be seen as lowering the fixed entry cost that establishments must pay in order to join a particular product market. The resulting increase in competition in the product market allows significant firm entry, which in turn lowers prices and raises the productivity level required for survival, as average productivity and wages rise. The smallest or least productive establishments are forced to exit the product space, and larger establishments increase their market shares. Alternatively, we can view the reservations policy as affecting the optimal behavior of multiproduct establishments. Larger establishments that may have found it optimal to produce reserved products may not have been able to do so when the reservations policy was in place, and thus may have switched to a more optimal allocation after the reforms. In addition, by raising competition, de-reservation may have pushed establishments to specialize in products in their core competence (Eckel and Neary 2010).

The remainder of the paper is organized as follows. Section I explains the rationale behind SSI reservation in India, describes the trends in reservation and de-reservation, and reviews the datasets used in estimation. Section II identifies the impacts of SSI reservation policies on employment, investment, output, and wages over the 2000 through 2007 period. Section III presents additional robustness checks. Section IV examines SSI policy through the lens of the size-age-growth relationship, and Section V concludes.

\section{Promoting Small and Medium Enterprises in India}

India has historically supported its small-scale sector. According to Mohan (2002), one major reason was the government's belief that employment generation is critical in a labor-surplus economy. Many believed that SSIs, particularly labor-intensive manufacturing enterprises, would be able to absorb surplus labor. One important pillar of the policy of SSI promotion was the reservation policy, initiated in 1967. Under this policy, which applies exclusively to manufacturing, certain products were reserved for production by SSIs. Initially only 47 items were reserved (see Figure 1), but by 1996 that number had grown to more than 1,000 products. Mohan points out that the only selection criterion mentioned in official documents was the ability of SSIs to manufacture such items. He also notes-as does the report of an expert committee on small enterprises - that the choice of products was "arbitrary" (Hussain 1997; Mohan 2002).

SSIs were originally defined as industrial undertakings with up to Rs 500,000 in fixed assets and fewer than 50 employees. 5 Over time, the employment condition was dropped and the investment ceiling was raised, so that by 1999, industrial undertakings with up to Rs 10 million in plant and machinery (at historical cost) were considered SSIs. ${ }^{6}$ Large industrial undertakings that already made the reserved

\footnotetext{
${ }^{5}$ An industrial undertaking may include more than one establishment. As we discuss below, almost all observations in our data include only one establishment, and we conduct our analysis at the establishment level.

6 Table A1 shows the evolution of SSI ceilings over time. The restriction on employment was dropped in 1960. The ceiling has been defined in terms of the original value of plant and machinery since 1966 . The ceiling on investment in plant and machinery was raised to Rs 30 million in 1997, but was subsequently reduced to Rs 10 million in
} 


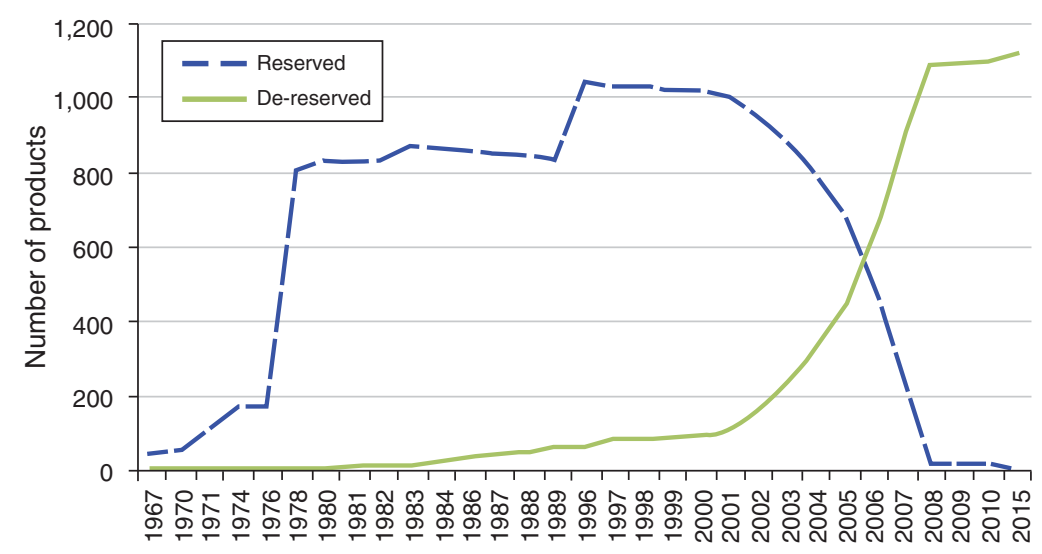

Figure 1. De-Reservation Policy

Notes: Data for 1967 through 1989 taken from Table 6.3 in Mohan (2002). Data for 1996 onward taken from various publications of the Government of India, Ministry of Micro, Small, and Medium Enterprises.

products were allowed to continue manufacturing them, but their output was capped at current levels. Any further expansion or entry required a commitment to export the majority of output (Mohan 2002).

Despite India's liberalization of a variety of industrial and trade policies in 1991, the reservation of products for SSIs remained in force until the late 1990s. However, the Advisory Committee on Reservation recognized growing concerns about SSI policies following the 1991 trade liberalization. SSIs had to compete with imported goods, and large undertakings (which had been grandfathered in) might be able to exercise monopoly power in the market for reserved goods, as most other producers would be small. Moreover, growing consumer demand for high-quality goods, and ongoing technological progress, made it more difficult to produce many items in small undertakings. The advisory committee therefore appointed a special committee to reconsider the list of reserved items in 1995 (Hussain 1997). Based on recommendations from this committee, product de-reservation began in 1997 (Figure 1 and online Appendix Table B.3). While there were a few items removed from the list in earlier years, large-scale de-reservation started in 1997 (15 products) and picked up in 2002 (51 products). From 2003 to 2008, approximately 100 to 250 products were de-reserved each year, with only 22 products remaining reserved at the end of that period. The greatest number of products (253) was de-reserved at the end of our sample period, in 2007.7 In 2015, the last products were removed from the reservation list.

1999. Banerjee and Duflo (2014) use these changes to examine the impact of directed credit on firm performance. In 2006, the Micro, Small and Medium Enterprise Act raised the limit on plant and machinery for small enterprises to Rs 50 million. We would therefore expect the constraint of the SSI reservation policy to be less binding for the last year of our sample.

${ }^{7}$ The coverage also accelerated in 2007 as there were many establishments making several products that were de-reserved in that year, the most common of which was "fire clay, bricks and blocks containing less than 40 percent alumina." Nearly 4,500 incumbent establishments were making these bricks. Other items de-reserved in 2007 were made by 200-500 incumbents each, which included sawn timber, bolts and nuts, reinforced cement concrete pipes, clay flooring tiles, shopping bags, and centrifugal pumps. It is not unusual in these types of reforms that the most 
We mapped the list of SSI products to a panel of manufacturing establishments from the Annual Survey of Industries (ASI) from 2000-2001 through 2007-2008 (for simplicity, we hereafter refer to these years as 2000 through 2007). ${ }^{8}$ The ASI provides a representative sample of all registered manufacturing establishments in India, with large establishments covered every year, and smaller establishments covered on a sampling basis. 9 While previously the ASI did not release identifiers that would allow researchers to follow the same unit across years, the Central Statistical Office recently reversed this policy and released a panel going back to 1998. However, due to incomplete product coverage in 1998 and 1999 we are forced to begin our analysis in 2000. We drop 1998 and 1999 because without detailed product coverage we cannot identify which establishments were affected by SSI reservations and which were not.

The basic unit of observation in the ASI is an establishment (called a factory in the ASI data). The ASI allows owners who have more than one establishment in the same state and industry to provide a joint return, but very few (less than 5 percent of our sample) do so, and our analysis is conducted at the level of the establishment. Establishments report products in the ASI survey using ASI Commodity Classification (ASICC) codes. We created a concordance between the SSI product codes - which indicate which products were reserved for small and medium enterprises - and the ASICC codes. We describe our procedure in online Appendix B.

Table 1 provides further details on the establishments in the ASI. Our dataset contains approximately 30,000 establishments in any given year, 26 percent of which made at least one reserved product in 2000. Table 1 documents that SSI reservation policies were pervasive at the beginning of the sample period and affected one out of four establishments in our sample. By 2007, however, less than 10 percent of establishments were making reserved products. Table 1 also shows that establishments making de-reserved products were, on average, slightly younger than establishments making reserved products.

One obvious question is how to assess the quality of the ASI data. The ASI has only recently been released with panel identifiers that allow us to track individual establishments over time. In online Appendix B, we show that there is a high level of consistency in opening and closing stock variables reported by a given establishment from year to year. This data quality is consistent across state, industry, time, and establishment size, and suggests that the ASI panel correctly identifies annual observations belonging to each establishment.

A number of researchers have instead used the Prowess database, which is created and maintained by the Centre for Monitoring Indian Economy (CMIE). The

products are deregulated at the end. For the dismantling of the Multi-Fibre Agreement, for example, most items were removed from the restricted list in the very last year of the reform.

${ }^{8}$ The ASI uses the accounting year, which runs from April 1 to March 31. We refer to each accounting year based on the start of the period; for example, the year we call "2000" runs from April 1, 2000 to March 31, 2001. Because the product de-reservation in 2008 took place at the tail end of the 2007-2008 accounting year, we do not count these products as being de-reserved during 2007-2008.

${ }^{9}$ From the 2000-2001 to 2002-2003 accounting years, the ASI census sector included all industrial units with 200 or more workers. In addition, all public sector units, and all units in 12 of India's least developed states were included in the census sector. Certain units with fewer than 200 workers, but with a large value of output, were also assigned to the census sector. Starting in accounting year 2003-2004, the census sector was modified to include all units with 100 or more workers, for both the private and public sectors. In addition, establishments in five of the least developed states were covered under the census sector. 
Table 1-Summary Statistics for ASI Manufacturing Establishments by Participation in Reserved Product Market

\begin{tabular}{|c|c|c|c|c|c|c|c|c|c|c|c|c|}
\hline \multirow[b]{3}{*}{2000} & \multicolumn{4}{|c|}{ Manufacturing reserved product } & \multicolumn{4}{|c|}{ Manufacturing de-reserved product } & \multicolumn{4}{|c|}{$\begin{array}{l}\text { Not manufacturing products that } \\
\text { were ever reserved }\end{array}$} \\
\hline & \multirow{2}{*}{$\begin{array}{c}\begin{array}{c}\text { Labor } \\
(000 \mathrm{~s})\end{array} \\
1,515\end{array}$} & \multirow{2}{*}{$\frac{\begin{array}{c}\text { Age } \\
(\text { mean })\end{array}}{16.4}$} & \multicolumn{2}{|c|}{ Establishments } & \multirow{2}{*}{$\begin{array}{r}\begin{array}{r}\text { Labor } \\
(000 \mathrm{~s})\end{array} \\
72\end{array}$} & \multirow{2}{*}{$\begin{array}{c}\begin{array}{c}\text { Age } \\
(\text { mean })\end{array} \\
17.3\end{array}$} & \multicolumn{2}{|c|}{ Establishments } & \multirow{2}{*}{$\begin{array}{c}\text { Labor } \\
(000 \mathrm{~s})\end{array}$} & \multirow{2}{*}{$\begin{array}{c}\begin{array}{c}\text { Age } \\
(\text { mean })\end{array} \\
19.3\end{array}$} & \multicolumn{2}{|c|}{ Establishments } \\
\hline & & & 8,040 & $26 \%$ & & & 1,327 & $4 \%$ & & & 21,483 & $70 \%$ \\
\hline 2001 & 1,355 & 16.8 & 7,995 & $24 \%$ & 306 & 13.7 & 2,433 & $7 \%$ & 3,616 & 19.0 & 22,505 & $68 \%$ \\
\hline 2002 & 1,384 & 16.9 & 8,293 & $25 \%$ & 353 & 14.6 & 2,820 & $9 \%$ & 3,626 & 19.4 & 21,966 & $66 \%$ \\
\hline 2003 & 1,311 & 16.7 & 10,194 & $23 \%$ & 601 & 15.7 & 4,247 & $10 \%$ & 3,863 & 18.5 & 30,006 & $68 \%$ \\
\hline 2004 & 1,085 & 17.1 & 8,153 & $21 \%$ & 857 & 15.8 & 4,685 & $12 \%$ & 3,711 & 18.8 & 25,606 & $67 \%$ \\
\hline 2005 & 936 & 16.9 & 7,797 & $19 \%$ & 1,177 & 15.6 & 6,106 & $15 \%$ & 3,990 & 17.7 & 27,976 & $67 \%$ \\
\hline 2006 & 752 & 16.2 & 6,981 & $17 \%$ & 1,471 & 15.6 & 6,782 & $16 \%$ & 4,190 & 17.0 & 27,444 & $67 \%$ \\
\hline 2007 & 452 & 17.4 & 3,229 & $9 \%$ & 1,908 & 16.3 & 8,806 & $24 \%$ & 4,407 & 17.1 & 24,148 & $67 \%$ \\
\hline
\end{tabular}

Notes: Summary statistics for all establishments are authors' calculations based on ASI data. No sampling multipliers applied. Labor is total for each group-year, in thousands. Age represents mean value for each group-year. Percentages indicate percent of total number of establishments producing reserved (or de-reserved) products in each given year.

Prowess database is useful for studying the behavior of large firms, including pricing and markups, privatization, firm size distribution and firm dynamics, the political economy of FDI liberalization, product switching, and the use of imported intermediate goods (see, among others, Gupta 2005; Chari and Gupta 2008; Alfaro and Chari 2009, 2014; Goldberg et al. 2010a, b; DeLoecker et al. 2016). However, since Prowess focuses on large firms, it would not be appropriate for our examination of a small-scale reservation policy. ${ }^{10}$

As our focus is on employment trends over time, the ASI data are by far the most comprehensive panel available for the Indian manufacturing sector. In 2000, the Prowess database listed output and capital data for over 7,000 firms, but only listed employment data for 90 firms, while the ASI had employment data on 30,850 establishments. By the end of our sample period, in 2007, the Prowess database had significantly improved its employment coverage to 774 firms, but it still lagged behind the ASI which reported employment data for 36,145 establishments. ${ }^{11}$ Mohanan and Chopra (2012) raise the concern that there are only 4,018 establishments that appear in all 10 years of the ASI panel for 1998 through 2007. For the period we consider (2000 through 2007), the ASI reports both wage and employment data for over 6,000 establishments over all 8 years. ${ }^{12}$ For the same eight-year period, Prowess does not have superior full-panel coverage: it reports wage data in every year for 4,474 firms and employment data in every year for 37 firms. ${ }^{13}$

\footnotetext{
${ }^{10}$ Another advantage of the ASI over Prowess is that the ASI reports the locations where establishments operate, whereas Prowess typically reports the headquarters location.

${ }^{11}$ A year-by-year comparison of ASI and Prowess coverage for our key variables is reported in online Appendix Table B.2.

${ }^{12}$ For shorter series, the ASI coverage is much greater. In part, this reflects the fact that the ASI also covers small establishments where there is a lot of churning (entry and exit).

${ }^{13}$ Another advantage of the ASI is that it allows us to observe even the smallest firms, albeit with lower sampling frequency and estimated sampling multipliers. There may be a concern that within-establishment regressions are not ideal for SSI analysis because smaller establishments are sampled less frequently than larger ones. We address this concern in three ways. First, we note that the SSI cutoff is capital-based whereas the sampling frame is labor-based. We therefore frequently observe establishments that may be large by labor standards but are small in terms of capital investment, and hence SSI, standards. Second, we look at a period that is long enough that even infrequently sampled establishments are likely to be observed at least twice. Specifically, 64 percent of the establishments observed making a reserved product while it was reserved make it into our establishment-level regressions. Third, we complement our establishment-level regressions with district-, product-, and, (in the online
} 
In summary, for the purposes of our analyses, the ASI data are the most comprehensive and appropriate panel available, and appear to be of reasonable quality. Online Appendix B includes further details on the nature and quality of the ASI panel.

\section{Removal of Small-Scale Reservation Policies}

In this section, we use the dismantling of the SSI reservation policy documented in Figure 1 to measure its impact on establishments of different sizes and ages. While we are particularly interested in the impact on employment, we also report consequences for investment, output, wages, and labor productivity. Legally, small-scale reservation policies applied primarily to establishments with a historical cost of plant and machinery below Rs 10 million during our sample years. Consequently we would expect a heterogeneous response to the removal of reservation policies across establishments depending on whether they were constrained by the Rs 10 million ceiling. 14

Our level of analysis is primarily at the establishment level. Subsequent sections demonstrate that our results are consistent across the district-, product-, and industry-levels of analysis.

\section{A. Establishment-Level Effects of De-Reservation}

When we classify an establishment as making a reserved or de-reserved product, we consider every product that the establishment makes, not just its main product. We begin by noting whether an establishment is ever observed making any product that was ever on the reserved list (regardless of whether it was de-reserved); we refer to these as SSI products. For 92 percent of establishments that ever make an SSI product, this procedure identifies only one product, which we call the establishment's main SSI product. 15

The main SSI product assigned to an establishment does not change over time. Rather, the variable Deres goes from 0 to 1 when the product is de-reserved. We start with a difference-in-differences (DID) equation of the following form for establishment $i$ in year $t$ :

$$
y_{i t}=\beta \text { Deres }_{i t}+\alpha_{i}+\alpha_{t}+\omega_{i t}
$$

\footnotetext{
Appendix), industry-level regressions, that include every establishment, even those observed only once. Our results are robust to these different specifications.

${ }^{14}$ As noted above, in 2006, the Micro, Small and Medium Enterprise Act raised the limit on plant and machinery for small enterprises to Rs 50 million. However, since this change was only made official in September 2006, and our sample period only extends to 2007 , we focus on the Rs 10 million threshold.

${ }^{15}$ For the remaining 8 percent of establishments that ever make an SSI product, this procedure identifies multiple SSI products. In about 40 percent of those cases, the multiple products were de-reserved in the same year, so the difference does not affect our results. In the remaining cases, establishments are observed producing more than one reserved product with different years of de-reservation. In the establishment-level regressions we attribute to those establishments the year of de-reservation that comes first. In the district-level, industry-level and product-level regressions, we aggregate from the product-level rather than the establishment-level, so we assign year of de-reservation to each specific product.
} 
The dependent variable $y_{i t}$ is alternatively defined as the (log of) employment, output, capital, the average per-employee wage, or labor productivity (output/ employee) of establishment $i$ at time $t$. Employment is defined as the total number of employees. Throughout the paper, output and capital are defined in real terms, where output is deflated by the wholesale price index (WPI) for the appropriate product category, and capital is deflated by the WPI for plant and machinery. Wages are measured by dividing the total annual wage bill, deflated by the consumer price index, by the number of employees. We also measure labor productivity as real output divided by the number of employees.

Deres $_{i t}$ is a dummy variable that is equal to 1 if the establishment's main SSI product has been de-reserved. Where possible, we include all establishments-even those that do not help to identify $\beta$ because they are not affected by the reservation policy-because these establishments help to identify the secular year trends in establishment performance.

Because we are controlling for both year $\left(\alpha_{t}\right)$ and establishment $\left(\alpha_{i}\right)$ fixed effects, $\beta$ is identified from a combination of (i) products becoming de-reserved and (ii) establishments switching into making (de)reserved products. To distinguish between these channels, we classify establishments based on whether they are incumbents and entrants into the product market. We create a dummy variable Incumbent that equals 1 if an establishment ever made an SSI product before it was de-reserved. Similarly, we create a dummy variable Entrant that equals 1 if an establishment ever made an SSI product after it was de-reserved, but not before. Both incumbent and entrant status are time-invariant. Note that our establishment fixed effects absorb the direct impacts of being an incumbent or entrant, so we interact the Deres variable with indicator variables for Incumbent and Entrant:

$$
\begin{aligned}
y_{i t}= & \gamma \text { Deres }_{i t} \times \text { Incumbent }_{i}+\rho \text { Deres }_{i t} \times \text { Entrant }_{i}+\alpha_{t}+\text { EntryYear }_{i} * \alpha_{t} \\
& +\alpha_{i}+\epsilon_{i t} .
\end{aligned}
$$

In all of our establishment-level regressions, we recognize that establishments entering into a new product space may be fundamentally different from those that do not. We address this possible selection in two ways. First, we identify the first year in which we see an establishment switching the main product that it makes (regardless of whether it is an SSI product). ${ }^{16}$ We assign the establishment this Entry Year into a new product space. When we separate results by incumbents and entrants, we control for an interaction between this year of entry and year fixed effects. This creates a nonparametric control for unobserved, time-varying characteristics for establishments that switched into new product spaces in each year. ${ }^{17}$ In an alternate specification, discussed in Section III and shown in Table 10, we control for whether an establishment changes the main product it makes in any given year. With these two sets of controls, we interpret the coefficients for entrants as the effect of de-reservation conditional on the decision to enter a new product space.

\footnotetext{
${ }^{16}$ We do not count this as a switch if the establishment immediately switches back to making the original product.

${ }^{17}$ Our results are robust to using a separate linear time trend for each year of entry into a new product space.
} 
Table 2-Impact of De-Reservation on Establishment-Level Outcomes

\begin{tabular}{|c|c|c|c|c|c|}
\hline & $\log$ (labor) & $\log ($ output $)$ & $\log ($ capital $)$ & $\log ($ wage $)$ & $\log (\mathrm{Q} / \mathrm{L})$ \\
\hline \multicolumn{6}{|l|}{ Panel A. Aggregate results } \\
\hline$t \geq$ year de-reserved & $\begin{array}{r}-0.00428 \\
(0.00862)\end{array}$ & $\begin{array}{c}0.0232 \\
(0.0120)\end{array}$ & $\begin{array}{c}0.00628 \\
(0.00992)\end{array}$ & $\begin{array}{l}0.0131 \\
(0.00485)\end{array}$ & $\begin{array}{l}0.0158 \\
(0.00973)\end{array}$ \\
\hline Establishment fixed effects & Yes & Yes & Yes & Yes & Yes \\
\hline Year fixed effects & Yes & Yes & Yes & Yes & Yes \\
\hline Observations & 298,984 & 294,157 & 292,998 & 296,575 & 294,157 \\
\hline Establishments & 130,397 & 128,033 & 127,822 & 128,986 & 128,033 \\
\hline$R^{2}$ & 0.006 & 0.011 & 0.003 & 0.026 & 0.007 \\
\hline \multicolumn{6}{|l|}{ Panel B. Incumbents versus entrants } \\
\hline Incumbent $\times t \geq$ year de-reserved & $\begin{array}{l}-0.0211 \\
(0.00948)\end{array}$ & $\begin{array}{c}-0.0183 \\
(0.0128)\end{array}$ & $\begin{array}{c}-0.0110 \\
(0.0106)\end{array}$ & $\begin{array}{c}0.00109 \\
(0.00508)\end{array}$ & $\begin{array}{c}-0.0151 \\
(0.0102)\end{array}$ \\
\hline Entrant $\times t \geq$ year de-reserved & $\begin{array}{c}0.0733 \\
(0.0193)\end{array}$ & $\begin{array}{l}0.230 \\
(0.0325)\end{array}$ & $\begin{array}{c}0.0853 \\
(0.0254)\end{array}$ & $\begin{array}{c}0.0703 \\
(0.0138)\end{array}$ & $\begin{array}{l}0.179 \\
(0.0275)\end{array}$ \\
\hline Establishment fixed effects & Yes & Yes & Yes & Yes & Yes \\
\hline Year fixed effects & Yes & Yes & Yes & Yes & Yes \\
\hline Year of entry $\times$ year fixed effects & Yes & Yes & Yes & Yes & Yes \\
\hline Observations & 298,984 & 294,157 & 292,998 & 296,575 & 294,157 \\
\hline Establishments & 130,397 & 128,033 & 127,822 & 128,986 & 128,033 \\
\hline$R^{2}$ & 0.008 & 0.014 & 0.004 & 0.027 & 0.009 \\
\hline
\end{tabular}

Notes: Results from establishment-level regressions. Dependent variables are shown in column headings. " $t \geq$ year de-reserved" is a dummy variable that takes a value of 1 if the product associated with the establishment is removed from the list of reserved products. Incumbent indicates that the establishment previously made the product when it had reserved status. Entrant indicates that the establishment only made the product after it had been de-reserved. In panel B we control for the interaction between year of entry and year fixed effects, where the year of entry is the first year in which we see an establishment switching the main product that it makes (regardless of whether it is an SSI product or not). Q/L indicates labor productivity (real output divided by number of employees). Errors are clustered at the establishment level.

While we do not control for potentially confounding policy changes, other major reforms with heterogeneous effects across manufacturing products were limited during this time period. By 1998, 93 percent of industries were no longer subject to licensing requirements. Major changes in policies vis-à-vis foreign investment occurred in the early 1990s, and then stalled during the period of SSI reform. Nataraj (2011) shows that tariffs were largely harmonized across industries by the late 1990s, so even though there were some reductions during the 2000s the variation in tariff rates across product types had fallen dramatically by the start of the sample period.

Our establishment-level results from estimating equations (1) and (2) are reported in Table 2. The point estimates in panel A of Table 2 indicate that when we do not distinguish between incumbents and entrants, de-reservation across the entire sample of establishments had no statistically significant impact on employment or capital. However, removal of small-scale reservation was associated with a significant increase in the per-employee wage and a marginally significant increase in output. The coefficients on output and wages indicate that on average across all establishments, the removal of small-scale reservation was associated with a 2.4 percent increase in output and a 1.3 percent increase in the average (real) wage. ${ }^{18}$

\footnotetext{
${ }^{18}$ Changes are estimated as $[\exp (b)-1]$ for each coefficient $b$.
} 
These averages mask considerable heterogeneity among incumbents and entrants. Panel B of Table 2 shows that for entrants into a previously reserved product space, employment, output, capital investment, wages, and labor productivity increased significantly. Employment increased by 7.7 percent, output by 26 percent, and capital investment by 9 percent. Average real wages increased by 7 percent. In keeping with the relatively large increase in output relative to employment, labor productivity increased by nearly 20 percent.

For incumbents that previously produced reserved products and remained in the sample, the coefficients on all outcome variables are smaller in magnitude and, with the exception of the employment results, statistically indistinguishable from zero. The coefficient on employment is significant and negative, suggesting that de-reservation is associated with a 2.1 percent decrease in employment among incumbents. These findings suggest that with de-reservation, the average incumbent shrank, while the average entrant grew. 19

\section{B. Endogeneity of De-Reservation Timing}

Our baseline specifications include establishment fixed effects, which control for any time-invariant, establishment-level characteristics that are correlated with de-reservation. Furthermore, all SSI products were eventually de-reserved by 2015. Therefore, we are not concerned that certain SSI products, but not others, were strategically chosen for de-reservation.

However, since our identification strategy exploits the differential timing of de-reservation, one potential concern is that products were strategically chosen for de-reservation during certain years. Documents from the Ministry of Micro, Small and Medium Enterprises indicate that products were de-reserved based on the recommendations of a special committee. Committee members were asked to consider a variety of factors when determining which products to de-reserve, including the labor intensity of production, the minimum economic scale of production, and consumer interests. ${ }^{20}$ Critically, the committee indicated that some products were selected for de-reservation based on recent changes in product innovation. Therefore, it is possible that the product markets for de-reserved items were changing in a systematically different way than the markets for non-de-reserved items.

To address this concern, we rerun our establishment level regressions controlling for product-level event-time trends. Specifically, we create an event-time variable, $\tau$, which is equal to the year of de-reservation minus the current year. $\tau$ equals -1 in the year prior to de-reservation, 0 in the year of de-reservation, 1 in the year following de-reservation, and so forth. $\tau$ is set equal to 0 for any establishments that do not make a reserved product. We reestimate equations (1) and (2) including this

\footnotetext{
${ }^{19}$ Joint $F$-tests reject that the coefficients on incumbents and entrants are the same for all outcomes.

${ }^{20}$ The special committee produced a report identifying products for de-reservation. This report indicated a number of reasons for selecting the first set of products recommended for de-reservation, namely: feasibility of producing quality products given the threshold on investment; need for higher investment due to product innovation; safety and hygiene issues associated with certain products; export potential; resource utilization; and the creation of a "monopoly like situation" in certain product markets due to the Carry On Business licenses granted to large establishments (Hussain 1997).
} 
Table 3-Impact of De-Reservation on Establishment-Level Outcomes, Controlling for Time Trend

\begin{tabular}{|c|c|c|c|c|c|}
\hline & $\log ($ labor $)$ & $\log ($ output $)$ & $\log ($ capital $)$ & $\log ($ wage $)$ & $\log (\mathrm{Q} / \mathrm{L})$ \\
\hline \multicolumn{6}{|l|}{ Panel A. Aggregate results } \\
\hline$t \geq$ year de-reserved & $\begin{array}{c}-0.000590 \\
(0.00896)\end{array}$ & $\begin{array}{c}0.0371 \\
(0.0125)\end{array}$ & $\begin{array}{c}-0.00954 \\
(0.0106)\end{array}$ & $\begin{array}{c}0.0129 \\
(0.00511)\end{array}$ & $\begin{array}{c}0.0232 \\
(0.0103)\end{array}$ \\
\hline Time relative to de-reservation & $\begin{array}{c}-0.00151 \\
(0.00182)\end{array}$ & $\begin{array}{r}-0.00566 \\
(0.00268)\end{array}$ & $\begin{array}{c}0.00645 \\
(0.00252)\end{array}$ & $\begin{array}{c}0.00009 \\
(0.00101)\end{array}$ & $\begin{array}{r}-0.00302 \\
(0.00213)\end{array}$ \\
\hline Establishment fixed effects & Yes & Yes & Yes & Yes & Yes \\
\hline Year fixed effects & Yes & Yes & Yes & Yes & Yes \\
\hline Observations & 298,984 & 294,157 & 292,998 & 296,575 & 294,157 \\
\hline Establishments & 130,397 & 128,033 & 127,822 & 128,986 & 128,033 \\
\hline$R^{2}$ & 0.006 & 0.011 & 0.003 & 0.026 & 0.007 \\
\hline \multicolumn{6}{|l|}{ Panel B. Incumbents versus entrants } \\
\hline Incumbent $\times t \geq$ year de-reserved & $\begin{array}{c}-0.0146 \\
(0.00976)\end{array}$ & $\begin{array}{c}-0.000433 \\
(0.0132)\end{array}$ & $\begin{array}{c}-0.0244 \\
(0.0113)\end{array}$ & $\begin{array}{c}0.00117 \\
(0.00536)\end{array}$ & $\begin{array}{c}-0.00566 \\
(0.0107)\end{array}$ \\
\hline Entrant $\times t \geq$ year de-reserved & $\begin{array}{c}0.0798 \\
(0.0196)\end{array}$ & $\begin{array}{l}0.249 \\
(0.0327)\end{array}$ & $\begin{array}{c}0.0718 \\
(0.0257)\end{array}$ & $\begin{array}{c}0.0704 \\
(0.0138)\end{array}$ & $\begin{array}{l}0.189 \\
(0.0277)\end{array}$ \\
\hline Time relative to de-reservation & $\begin{array}{r}-0.00264 \\
(0.00182)\end{array}$ & $\begin{array}{r}-0.00732 \\
(0.00269)\end{array}$ & $\begin{array}{c}0.00545 \\
(0.00253)\end{array}$ & $\begin{array}{c}-0.00004 \\
(0.00101)\end{array}$ & $\begin{array}{r}-0.00386 \\
(0.00214)\end{array}$ \\
\hline Establishment fixed effects & Yes & Yes & Yes & Yes & Yes \\
\hline Year fixed effects & Yes & Yes & Yes & Yes & Yes \\
\hline Year of entry $\times$ year fixed effects & Yes & Yes & Yes & Yes & Yes \\
\hline Observations & 298,984 & 294,157 & 292,998 & 296,575 & 294,157 \\
\hline Establishments & 130,397 & 128,033 & 127,822 & 128,986 & 128,033 \\
\hline$R^{2}$ & 0.008 & 0.014 & 0.004 & 0.027 & 0.009 \\
\hline
\end{tabular}

Notes: Results from establishment-level regressions. Dependent variables are shown in column headings. " $t \geq$ year de-reserved" is a dummy variable that takes a value of 1 if the product associated with the establishment is removed from the list of reserved products. Incumbent indicates that the establishment previously made the product when it had reserved status. Entrant indicates that the establishment only made the product after it had been de-reserved. Time relative to de-reservation is an event time trend that equals the year of de-reservation minus the current year (and is always equal to 0 for establishments that never made SSI products). In panel B we control for the interaction between year of entry and year fixed effects, where the year of entry is the first year in which we see an establishment switching the main product that it makes (regardless of whether it is an SSI product or not). $\mathrm{Q} / \mathrm{L}$ indicates labor productivity (real output divided by number of employees). Errors are clustered at the establishment level.

event-time variable, thereby controlling for any potential preexisting, linear trend in the outcome of interest in the years prior to de-reservation:

(1a) $y_{i t}=\beta$ Deres $_{i t}+\tau_{i t}+\alpha_{i}+\alpha_{t}+\omega_{i t}$

(2a) $\quad y_{i t}=\gamma$ Deres $_{i t} \times$ Incumbent $_{i}+\rho$ Deres $_{i t} \times$ Entrant $_{i}+\tau_{i t}+\alpha_{t}$

$$
+ \text { EntryYear }_{i} * \alpha_{t}+\alpha_{i}+\epsilon_{i t} .
$$

Table 3 shows that the baseline results are robust to controlling for these trends. In panel A, the coefficient on output is larger and statistically significant at a higher level (1 percent instead of 10 percent). Because of the larger increase in output, the coefficient on labor productivity also rises and is now statistically significant at the 5 percent level. The coefficients on labor and capital remain indistinguishable from zero, and the coefficient on wage is nearly unchanged. 
In panel B, the coefficient on labor for incumbents becomes less negative and statistically insignificant at conventional levels, whereas the coefficient on capital for incumbents becomes more negative in magnitude and statistically significant. For entrants, we continue to see a strong, positive relationship between de-reservation and all outcomes, with similar magnitudes and statistical significance.

\section{Effects of De-Reservation by Establishment Size and Age}

We now explore whether the impacts of de-reservation differed by establishment size and age. We measure size based on the historical value of fixed assets, which was used as a threshold to determine eligibility for the manufacture of reserved products.

Reserved products could typically be produced only by "industrial undertakings" with historical values of plant and machinery (P\&M) below a certain value. However, undertakings with historical capital investment above the threshold could produce reserved products if they committed to exporting a majority of production. Moreover, large incumbent undertakings (those that were already manufacturing the product before it was reserved, or small incumbent undertakings that grew above the threshold) could obtain a Carry On Business license to continue production. However, these undertakings were constrained to produce no more than they had previously produced.

Table 4 shows how the effect of de-reservation varied for establishments that reported average book values of P\&M above versus below the Rs 10 million threshold prior to de-reservation. In this table, we limit the sample to establishments where we observe plant and machinery in at least one year prior to de-reservation. ${ }^{21}$ In panel A, we find that de-reservation reduced employment among establishments that were previously below the threshold. The point estimate is significant, and indicates that on average these establishments reduced employment by 4.1 percent. However, the reforms increased employment, output, capital, and wages among constrained establishments, defined as those that had exceeded the 10 million Rs threshold. For these establishments, the increase in employment averaged 5 percent, while output increased by 6 percent.

In panel $\mathrm{B}$, we split the results by incumbents versus entrants. Incumbents with plant and machinery within the SSI cap prior to the reforms significantly reduced employment and output by nearly 6 percent, and labor productivity declined. In contrast, entrants over the SSI cap increased employment by 13 percent and output by over 15 percent. Larger incumbents that were presumably grandfathered, and constrained by historical output levels, also exhibited significant increases in employment, output, and wages. These positive results for larger incumbents are particularly interesting because they indicate that the driving mechanism for employment generation is not the distinction between entrants and incumbents, but the size constraints imposed on larger establishments.

\footnotetext{
${ }^{21}$ This restriction does not exclude entrants, because we do not require that the establishment be observed making the reserved product prior to de-reservation. For example, if an entrant started to make tapioca flour after it was de-reserved in 2004, and we observed that entrant's plant and machinery prior to 2004 (when it was making other products), then we include it.
} 
Table 4-Impact of De-Reservation on Establishment-Level Outcomes, By Value of Plant and Machinery

\begin{tabular}{|c|c|c|c|c|c|}
\hline & $\log ($ labor $)$ & $\log ($ output $)$ & $\log ($ capital $)$ & $\log ($ wage $)$ & $\log (\mathrm{Q} / \mathrm{L})$ \\
\hline \multicolumn{6}{|l|}{ Panel A. Aggregate results } \\
\hline Within SSI cap $\times t \geq$ year de-reserved & $\begin{array}{c}-0.0421 \\
(0.0104)\end{array}$ & $\begin{array}{c}-0.0116 \\
(0.0145)\end{array}$ & $\begin{array}{c}-0.00683 \\
(0.0122)\end{array}$ & $\begin{array}{c}0.00599 \\
(0.00599)\end{array}$ & $\begin{array}{c}0.0140 \\
(0.0119)\end{array}$ \\
\hline Over SSI cap $\times t \geq$ year de-reserved & $\begin{array}{c}0.0509 \\
(0.0144)\end{array}$ & $\begin{array}{c}0.0602 \\
(0.0201)\end{array}$ & $\begin{array}{c}0.0364 \\
(0.0155)\end{array}$ & $\begin{array}{l}0.0273 \\
(0.00758)\end{array}$ & $\begin{array}{r}0.00938 \\
(0.0160)\end{array}$ \\
\hline Establishment fixed effects & Yes & Yes & Yes & Yes & Yes \\
\hline Year fixed effects & Yes & Yes & Yes & Yes & Yes \\
\hline Current age group fixed effects & Yes & Yes & Yes & Yes & Yes \\
\hline Observations & 268,162 & 263,875 & 266,285 & 266,194 & 263,875 \\
\hline Establishments & 112,864 & 110,772 & 112,647 & 111,697 & 110,772 \\
\hline$R^{2}$ & 0.021 & 0.031 & 0.004 & 0.046 & 0.016 \\
\hline \multicolumn{6}{|l|}{ Panel B. Incumbents versus entrants } \\
\hline $\begin{array}{l}\text { Incumbent } \times \text { within SSI cap } \times \\
t \geq \text { year de-reserved }\end{array}$ & $\begin{array}{c}-0.0571 \\
(0.0113)\end{array}$ & $\begin{array}{r}-0.0603 \\
(0.0150)\end{array}$ & $\begin{array}{r}-0.0255 \\
(0.0130)\end{array}$ & $\begin{array}{r}-0.00947 \\
(0.00622)\end{array}$ & $\begin{array}{r}-0.0264 \\
(0.0122)\end{array}$ \\
\hline $\begin{array}{l}\text { Entrant } \times \text { within SSI cap } \times \\
\quad t \geq \text { year de-reserved }\end{array}$ & $\begin{array}{c}0.0162 \\
(0.0243)\end{array}$ & $\begin{array}{l}0.236 \\
(0.0442)\end{array}$ & $\begin{array}{c}0.0759 \\
(0.0339)\end{array}$ & $\begin{array}{c}0.0892 \\
(0.0182)\end{array}$ & $\begin{array}{l}0.243 \\
(0.0375)\end{array}$ \\
\hline $\begin{array}{c}\text { Incumbent } \times \text { over SSI cap } \times \\
t \geq \text { year de-reserved }\end{array}$ & $\begin{array}{c}0.0391 \\
(0.0162)\end{array}$ & $\begin{array}{c}0.0456 \\
(0.0228)\end{array}$ & $\begin{array}{c}0.0234 \\
(0.0171)\end{array}$ & $\begin{array}{l}0.0258 \\
(0.00833)\end{array}$ & $\begin{array}{r}0.00351 \\
(0.0179)\end{array}$ \\
\hline $\begin{array}{c}\text { Entrant } \times \text { over SSI cap } \times \\
t \geq \text { year de-reserved }\end{array}$ & $\begin{array}{l}0.128 \\
(0.0287)\end{array}$ & $\begin{array}{c}0.154 \\
(0.0389)\end{array}$ & $\begin{array}{c}0.0923 \\
(0.0353)\end{array}$ & $\begin{array}{c}0.0322 \\
(0.0178)\end{array}$ & $\begin{array}{c}0.0441 \\
(0.0336)\end{array}$ \\
\hline Establishment fixed effects & Yes & Yes & Yes & Yes & Yes \\
\hline Year fixed effects & Yes & Yes & Yes & Yes & Yes \\
\hline Year of entry $\times$ year fixed effects & Yes & Yes & Yes & Yes & Yes \\
\hline Current age group fixed effects & Yes & Yes & Yes & Yes & Yes \\
\hline Observations & 268,162 & 263,875 & 266,285 & 266,194 & 263,875 \\
\hline Establishments & 112,864 & 110,772 & 112,647 & 111,697 & 110,772 \\
\hline$R^{2}$ & 0.023 & 0.033 & 0.005 & 0.047 & 0.018 \\
\hline
\end{tabular}

Notes: Results from establishment-level regressions. Dependent variables are shown in column headings. " $t \geq$ year de-reserved" is a dummy variable that takes a value of 1 if the product associated with the establishment is removed from the list of reserved products. Within/over SSI cap refers to whether an establishment's average estimated value of plant and machinery in years pre-de-reservation exceeded Rs 10 million. Incumbent indicates that the establishment previously made the product when it had reserved status. Entrant indicates that the establishment only made the product after it had been de-reserved. In panel B we control for the interaction between year of entry and year fixed effects, where the year of entry is the first year in which we see an establishment switching the main product that it makes (regardless of whether it is an SSI product or not). Q/L indicates labor productivity (real output divided by number of employees). Errors are clustered at the establishment level.

We also find a large increase in output among entrants who would have been within the threshold (and thus allowed to enter the product space) even before de-reservation. One likely reason is that the product reservations discouraged even small establishments from entering the product space, since they would have known that they could not grow beyond a certain limit. Another possibility is that there may have been monopolistic conditions created by large, grandfathered incumbents. Once reservations were lifted and de-reserved product markets became more competitive, smaller establishments entered and grew. These small entrants increased output by over 25 percent and capital stock by 8 percent, with insignificant increases in employment. Thus, labor productivity and wages among these small entrants also increased substantially. 


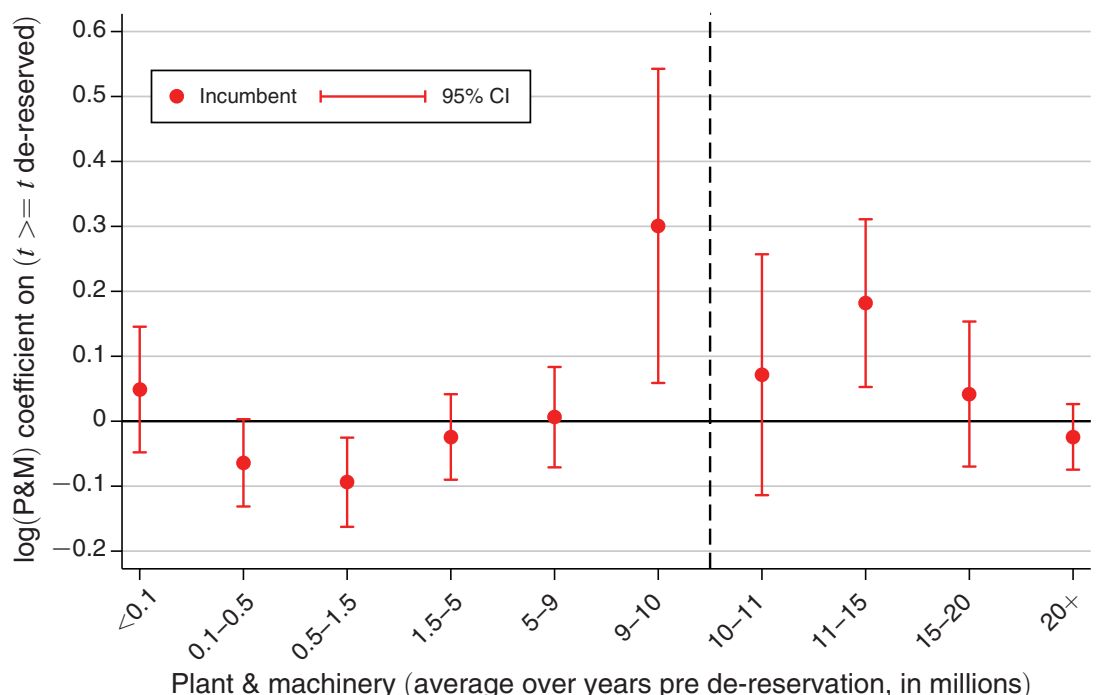

Figure 2. Impact of De-Reservation among Incumbent Establishments near the InVestment Threshold

Notes: Coefficients from a regression of $\log$ of nominal plant and machinery value on de-reservation, for incumbents in the product space. Establishments with historical investment in plant and machinery up to Rs 10 million (illustrated by the dashed line) could be considered small-scale industries.

We would expect that if the SSI threshold were a binding constraint prior to the reforms, the most productive incumbent establishments would have grown until they reached the threshold. Incumbent establishments just below the threshold, and those that reached the threshold and were granted Carry on Business licenses should benefit most from de-reservation. Figure 2 shows the effects of de-reservation across size categories of plant and machinery $(\mathrm{P} \& \mathrm{M})$ for incumbent establishments. The horizontal axis shows the average, pre-de-reservation P\&M size category, and the vertical axis shows the regression coefficients from the interaction between the pre-de-reservation P\&M size category and the de-reservation dummy, for incumbents. The results show that the largest effects are observed for establishments that were just below the Rs 10 million threshold. Figure 2 suggests that incumbents just below the threshold, with between 9 million and 10 million Rs in historical value of plant and machinery, were in fact constrained by the reservation policy, and increased their capital investment the most after de-reservation. Investment by incumbents just above the threshold also increased.

Figure 3 further examines the role of size as well as age. We reestimate equation (1), interacting the de-reservation indicator with dummy variables for multiple size categories of $\mathrm{P} \& \mathrm{M}$ and age categories. The two horizontal axes show the average, pre-de-reservation P\&M size and age categories, and the vertical axis shows the regression coefficients from the interaction between the size/age categories and the de-reservation dummy. This figure confirms that larger establishments grew faster with de-reservation, while smaller establishments shrank, with growth concentrated among younger age classes.

On average, establishments with more than 10 million Rs in $\mathrm{P} \& \mathrm{M}$ prior to de-reservation showed employment growth following de-reservation. Within each 


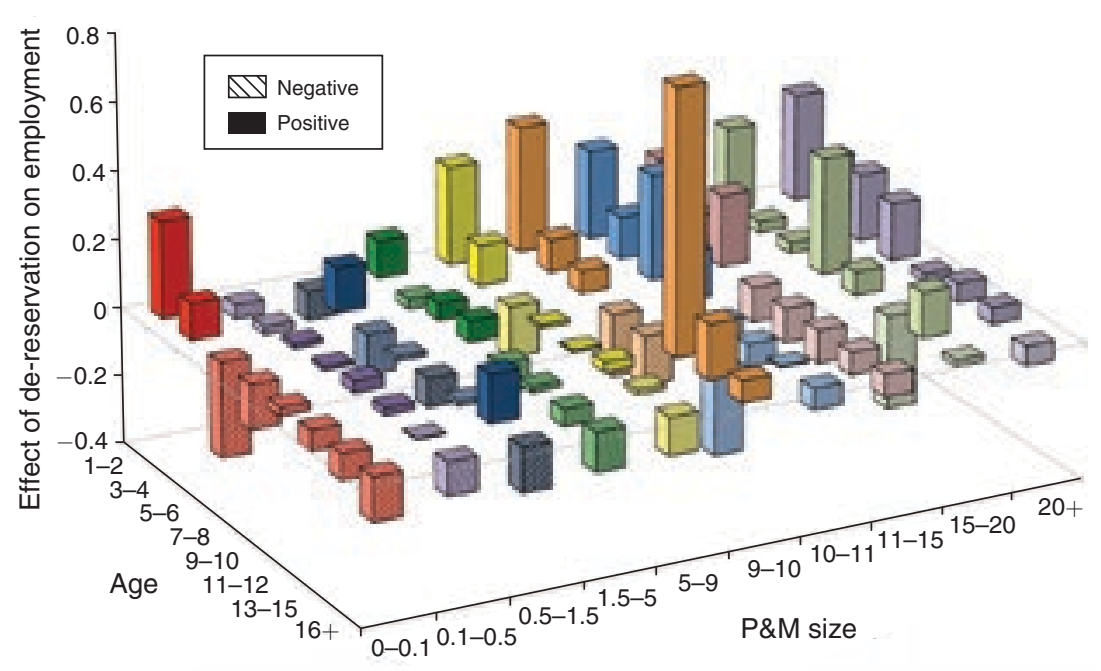

Figure 3. Impact of De-Reservation on Employment by Size and Age

Notes: Coefficients from a regression of log of employment on de-reservation, interacted with a dummy variable for each P\&M size and age class. P\&M size and age are measured as the average in years prior to de-reservation. Establishments with historical investment in plant and machinery up to Rs 10 million could be considered small-scale industries.

of these larger size classes, the fastest growing establishments were typically the younger ones. Conversely, for establishments previously below the 10 million Rs threshold, the coefficient on de-reservation is negative for many size and age categories. However, establishments with P\&M between 9 and 10 million Rs-those that were just below the threshold, and were therefore likely to have been constrained by it - saw some of the largest increases in employment with de-reservation. Notably, most other growth among small establishments was concentrated among young establishments. The establishments most negatively affected in terms of employment contraction were the smallest, oldest ones.

Taken together, these findings suggest that de-reservation increased the tendency of larger, younger establishments to grow relative to smaller, older establishments. The growth in employment was driven both by entrants that moved into the previously reserved product space, as well as by large incumbents that were previously constrained by the reservation ceiling.

\section{Product-Level Analysis}

Our identification strategy relies on changes in employment and other outcomes in establishments observed both before and after de-reservation. However, because the ASI includes a census of all large establishments each year, but only covers a subset of smaller establishments, the sample of establishments that we observe both before and after de-reservation is not representative of the entire universe of ASI establishments, and is biased toward larger establishments. In our sample, median employment among establishments making reserved, SSI products and reporting 
Table 5-Impact of De-Reservation on Product-Level Outcomes

\begin{tabular}{lcccccc}
\hline \hline & $\log ($ labor $)$ & $\log ($ output $)$ & $\log ($ capital $)$ & $\log ($ wage $)$ & $\log (\mathrm{Q} / \mathrm{L})$ & $\log ($ estab $)$ \\
\hline$t \geq$ year de-reserved & 0.423 & 0.295 & 0.378 & 0.0593 & -0.128 & 0.136 \\
& $(0.0785)$ & $(0.0650)$ & $(0.0964)$ & $(0.0218)$ & $(0.0586)$ & $(0.0549)$ \\
Product fixed effects & Yes & Yes & Yes & Yes & Yes & Yes \\
Year fixed effects & Yes & Yes & Yes & Yes & Yes & Yes \\
Observations & 29,494 & 29,494 & 29,474 & 29,493 & 29,494 & 29,543 \\
Products & 4,126 & 4,126 & 4,126 & 4,126 & 4,126 & 4,126 \\
$R^{2}$ & 0.020 & 0.018 & 0.011 & 0.009 & 0.080 & 0.009 \\
\hline
\end{tabular}

Notes: Results from product-level regressions. Dependent variables are shown in column headings. " $t \geq$ year de-reserved" is a dummy variable that takes a value of 1 when the product is removed from the list of reserved products. Q/L indicates labor productivity (real output divided by number of employees). Regressions are weighted by initial labor shares. Standard errors are clustered at the product level.

plant and machinery below Rs 10 million (the cutoff for SSI classification) is 23 workers, compared with 34 workers for establishments that do not make SSI products.

To study the net aggregate effect of the de-reservation taking into account all establishments, we redo the analysis at the product level. We conduct the following regression of outcome $y$ on a dummy variable for de-reservation at the product level $p$ :

$$
y_{p t}=\beta \text { Deres }_{p t}+\alpha_{p}+\alpha_{t}+\mu_{p t}
$$

We allocate output using reported product-level revenues. To construct product-level labor, capital, wage, and number of establishments, we allocate each of these variables based on the share of revenues associated with that product. We apply sampling multipliers to all infrequently sampled firms and weight the product level regressions using initial employment. Table 5 shows that de-reservation is associated with an increase in the number of establishments making a product, and with increases in labor, output, capital, and wages. The estimates suggest that product de-reservation was associated with an average increase in the number of establishments producing a product of nearly 15 percent. For products that were de-reserved, employment increased by 50 percent, output by nearly 35 percent, capital by 45 percent, and wages by 6 percent. These large effects are all significant at the 5 percent level, and most are significant at the 1 percent level. At the product level, the increase in labor is greater than the increase in output, leading to a fall in labor productivity.

We also use the product-level regressions to conduct two additional robustness tests. First, we again check for endogenous product choice by testing for significant trends at the product level in outcomes prior to the reform. We run a product-level regression of de-reservation (equal to 1 in the year of de-reservation) on lagged, first difference changes in the product-level outcomes of interest (employment, output, capital, and wages). If government officials took a product off the reservation list in response to increasing employment or output growth, then the coefficients in our regressions should be statistically significant.

Because some products were not observed in every year, we calculate the lagged first difference at time $t$ by taking the outcome in the previous period observed 
Table 6-Pre-De-Reservation Trends at the Product Level

\begin{tabular}{lcccc}
\hline \hline & $(1)$ & $(2)$ & $(3)$ & $(4)$ \\
\hline lag $\Delta$ labor & 0.001 & & & \\
& $(0.001)$ & & & \\
lag $\Delta$ output & & -0.00006 & & \\
& & $(0.0007)$ & 0.0003 & \\
lag $\Delta$ capital & & $(0.0006)$ & 0.0003 \\
lag $\Delta$ wage & & & $0.002)$ \\
& & & & 20,869 \\
Observations & 20,870 & 20,870 & 20,851 & 4,010 \\
Products & 4,010 & 4,010 & 4,010 & 0.02 \\
$R^{2}$ & 0.02 & 0.02 & 0.02 & \\
\hline
\end{tabular}

Notes: Results from product-level regressions of de-reservation (equal to 1 in the year of de-reservation) on lagged, first difference changes in labor, output, capital, and wage. The number of products and observations is fewer than in Table 5 because (i) we only observe lagged first-differences in outcomes for 2002-2007 and (ii) for de-reserved products we only include years until de-reservation in order to avoid picking up the effects of de-reservation. Regressions are weighted by initial labor shares. Standard errors are clustered at the product level.

$\left(t_{-} l a g\right)$, minus the outcome in the prior period observed $\left(t_{-} l a g 2\right)$, and dividing by the gap between $t \_l a g$ and $t \_l a g 2$. We then estimate the following:

(4) Deres $_{p t}=\beta\left(\frac{\text { Outcome }\left(t_{-} \text {lag }\right)_{p}-\text { Outcome }\left(t_{-} \text {lag } 2\right)_{p}}{t_{-} \text {lag }-t_{-} \text {lag } 2}\right)+\alpha_{p}+\alpha_{t}+\omega_{p t}$.

We include all products for which we observe lagged, first-differenced outcomes, even those that were never reserved or de-reserved. For products that were de-reserved, we limit the sample to years up to the year of de-reservation, so as not to include the effects of de-reservation. Table 6 shows the results. We find no evidence that pre-de-reservation trends in the outcomes differed systematically prior to the year of de-reservation. The point estimates are insignificant and close to 0 .

We also conduct a placebo test, in the spirit of Chetty, Looney, and Kroft (2009), by randomizing de-reservation across remaining products. To do so, we randomly select ASI products and attribute a year of de-reservation to them, mirroring the distribution of years of de-reservation for the true de-reserved products. We perform this exercise 100 times. For each iteration, we run the following regression for each outcome of interest:

$$
y_{p t}=\beta \text { Deres }_{p t}+\delta \text { Placebo Deres }_{p t}+\alpha_{p}+\alpha_{t}+\mu_{p t}
$$

Because products that were actually de-reserved could be selected for the placebo treatment, we control for true de-reservation in order to avoid confounding the placebo effect with the true treatment effect.

Table 7, panel A shows the results from one of our 100 placebo runs, while panel B summarizes the number of runs that were significantly above or below 0 at the 5 percent level, for each outcome of interest. For most outcomes, 10 or fewer runs were 
Table 7-Placebo Tests at the Product Level

\begin{tabular}{lcccccc}
\hline \hline & $\log ($ labor $)$ & $\log ($ output $)$ & $\log ($ capital $)$ & $\log ($ wage $)$ & $\log (\mathrm{Q} / \mathrm{L})$ & $\log ($ estab $)$ \\
\hline Panel A. Sample product-level placebo test & & & & & & \\
$t \geq$ year de-reserved & 0.420 & 0.293 & 0.371 & 0.0589 & -0.127 & 0.136 \\
& $(0.0786)$ & $(0.0654)$ & $(0.0965)$ & $(0.0218)$ & $(0.0587)$ & $(0.0551)$ \\
Placebo $t \geq$ year de-reserved & -0.144 & -0.0873 & -0.315 & -0.0185 & 0.0567 & -0.0363 \\
& $(0.121)$ & $(0.109)$ & $(0.164)$ & $(0.0452)$ & $(0.0597)$ & $(0.0638)$ \\
Product fixed effects & Yes & Yes & Yes & Yes & Yes & Yes \\
Year fixed effects & Yes & Yes & Yes & Yes & Yes & Yes \\
Observations & 29,494 & 29,494 & 29,474 & 29,493 & 29,494 & 29,543 \\
Products & 4,126 & 4,126 & 4,126 & 4,126 & 4,126 & 4,126 \\
$R^{2}$ & 0.020 & 0.018 & 0.011 & 0.009 & 0.080 & 0.009
\end{tabular}

Panel B. Results of 100 iterations of placebo sampling, number of estimates landing above, below, and within 95 percent confidence interval around 0

\begin{tabular}{lccc} 
& Above 0 & Below 0 & Insignificant \\
\cline { 2 - 4 } Labor & 2 & 2 & 96 \\
Output & 6 & 3 & 91 \\
Capital & 4 & 5 & 91 \\
Wage & 6 & 3 & 91 \\
Q/L & 12 & 5 & 83 \\
Establishments & 5 & 4 & 91
\end{tabular}

Panel C. Results of 100 iterations of placebo sampling for labor and output
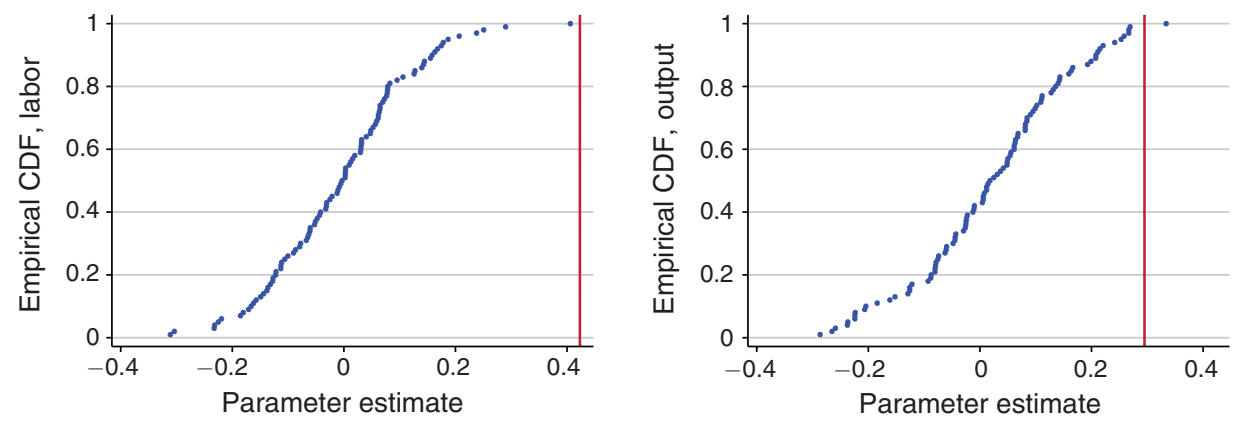

Notes: Results from a product-level placebo in which de-reservation is randomly assigned across all potential products. Placebos were assigned 100 times. Panel A shows an example of one placebo run. Panel B shows the number of runs in which each outcome of interest was above or below 0 and significant at the 5 percent level, versus not significant at the 5 percent level. Panel C shows an empirical cumulative distribution function (CDF) of 100 placebo runs, as well as the true coefficients, for labor and output. The vertical lines show the coefficients on true de-reservation. Standard errors are clustered at the product level.

significant at the 5 percent level, and those that were significant were fairly evenly split between positive and negative results. One outcome of interest-labor productivity - did exhibit 17 runs that were significantly different from 0,12 of which were positive, which is the opposite direction from our true results (see Table 5). Overall, 5.8 percent of the results were positive while 3.7 percent were negative. Panel $\mathrm{C}$ shows an empirical cumulative distribution function (CDF) from the 100 placebo results for employment and output. As expected with a successful placebo test, the true coefficients - shown by vertical lines-are at the far right of the CDF in each case. ${ }^{22}$

\footnotetext{
${ }^{22}$ We control for true de-reservation to avoid conflating true effects with false effects. However, we also tried the same placebo test without controlling for the real de-reservation, and results were similar. Overall around 5 percent of the results were positive while 5 percent were negative, again suggesting the absence of a placebo effect.
} 


\section{E. Net Impact of SSI Reservation Policies on District Outcomes}

The analyses above show that de-reservation increased employment among entrants to the newly de-reserved product spaces as well as large incumbents that were previously constrained by the SSI limits. In contrast, employment among small incumbents fell. In this section, we aggregate results on the net impact of de-reservation across entrants and incumbents in the product space as well as across different industries. We explore this net impact of de-reservation on overall manufacturing employment using the pretreatment allocation of reserved and nonreserved products at the district level.

Our measure of exposure to de-reservation is similar to that used by Topalova (2010) to study the impact of tariff liberalization on Indian districts. It exploits the fact that the de-reservation policy was implemented at a national level and varied across products, but calculates each district's exposure based on beginning-of-period product mix. Therefore, it avoids any changes in a district's product mix that may have been induced by the de-reservation policy. At the same time, it uses geographic variation in exposure to de-reservation, which is less likely to have influenced the special committee's decisions than product-level characteristics.

For each of the 339 districts in India that have at least 10 establishments reported in the ASI for each year in our sample, we construct a measure of exposure to de-reservation as follows:

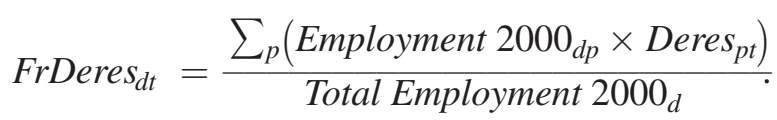

FrDeres $_{d t}$, the fraction of employment exposed to de-reservation, is calculated as the sum over all products $p$ of employment associated with that product in district $d$ in 2000, multiplied by a dummy variable indicating whether the product was de-reserved, and divided by total district-level employment in 2000. We allocate each establishment's employment to its various products based on output shares.

Panel A of Figure 4 shows the fraction of employment in each district that was associated with reserved products in 2000. Panel B shows the extent to which products were subsequently de-reserved by 2007 , weighting each de-reserved product by its labor share in 2000. The two figures illustrate the heterogeneity in coverage of product reservation across India. In 2000, prior to the bulk of the reforms, there was significant diversity in coverage across Indian districts. By 2007, the reforms had significantly affected all parts of India to varying degrees. This regional variation in intensity, based on preexisting exposure, is what allows us to identify the employment effects of the reform.

We estimate the following long-difference DID model at the district level:

$$
\Delta y_{d}=\beta \Delta \text { FrDeres }_{d}+\mu_{d}
$$

The left-hand-side variable, $\Delta y_{d}$ is alternatively the change in log of employment, output, capital, wages, or labor productivity between 2000 and 2007. The right-hand-side variable is the change in the fraction of employment exposed 
Panel A. Fraction of employment in 2000 associated with products ever reserved



Panel B. Fraction of employment in 2000 associated with products de-reserved, 1997-2007



Figure 4. Product Reservation and De-Reservation by District

Notes: Panel A shows the fraction of employment in 2000 that was associated with manufacturing a product that was ever reserved, by district. Panel B shows the fraction of employment in 2000 that was associated with manufacturing a product that was eventually de-reserved, by district. 
Table 8-Impact of De-Reservation on District-Level Outcomes: Long Differences, 2000-2007

\begin{tabular}{lccccc}
\hline \hline & $\Delta \log ($ labor $)$ & $\Delta \log ($ output $)$ & $\Delta \log ($ capital $)$ & $\Delta \log ($ wage $)$ & $\Delta \log (\mathrm{Q} / \mathrm{L})$ \\
\hline$\Delta$ fraction de-reserved & 0.785 & 0.741 & 0.649 & 0.160 & -0.0439 \\
& $(0.266)$ & $(0.323)$ & $(0.455)$ & $(0.132)$ & $(0.233)$ \\
$\Delta$ fraction de-reserved & -0.462 & -0.962 & -0.794 & -0.113 & -0.500 \\
in neighboring districts & $(0.394)$ & $(0.433)$ & $(0.575)$ & $(0.173)$ & $(0.300)$ \\
Pro-employer state & -0.0384 & -0.0889 & 0.220 & 0.0228 & -0.0506 \\
& $(0.0722)$ & $(0.0711)$ & $(0.0970)$ & $(0.0313)$ & $(0.0569)$ \\
Literacy (percent) & -0.00524 & -0.00298 & -0.0116 & 0.000202 & 0.00226 \\
& $(0.00358)$ & $(0.00341)$ & $(0.00595)$ & $(0.00173)$ & $(0.00286)$ \\
Scheduled caste/tribes (percent) & 0.00117 & -0.000701 & -0.00229 & 0.00144 & -0.00187 \\
& $(0.00241)$ & $(0.00251)$ & $(0.00315)$ & $(0.00127)$ & $(0.00217)$ \\
Control labor force composition & Yes & Yes & Yes & Yes & Yes \\
Observations & 339 & 339 & 339 & 339 & 339 \\
$R^{2}$ & 0.190 & 0.066 & 0.128 & 0.044 & 0.111 \\
\hline
\end{tabular}

Notes: Results from district-level regressions of changes in dependent variables (shown in column headings) from 2000-2007 on change in fraction of district employment in 2000 that was subsequently associated with product de-reservation. Fraction de-reserved is the fraction of a district's employment in 2000 that is subsequently associated with de-reservation. Fraction de-reserved in neighboring districts is the fraction of employment in contiguous districts in 2000 that is subsequently associated with de-reservation. Q/L indicates labor productivity (real output divided by number of employees). All specifications include a dummy equal to 1 if the state was classified as pro-employer at the end of the period studied by Besley and Burgess (2004). Specifications also control for the following characteristics from the 2001 census: the share of district's population that is scheduled caste/tribe, the percentage of literate population, and the percentage of workers in a district employed in agriculture, mining, manufacturing, trade, transport, and services (construction is the omitted category). Regressions are weighted by initial labor shares, and use all districts that, after applying weights, have at least 10 establishments in each ASI year. Errors are heteroskedasticity-robust.

to de-reservation between 2000 and 2007, where the fraction is calculated as described above. We calculate these variables at the district level by aggregating the establishment-level variables, inflated by their sampling weights. One potential concern is that the de-reservation may have resulted in interdistrict migration, thus affecting district-level results. To address this issue, we control for the average change in de-reservation among neighboring districts. We also control for whether the district is located in a state with employer-friendly regulations (as classified by Besley and Burgess 2004), and for a variety of preexisting, district-level characteristics based on the 2001 census.

Table 8 shows the district-level DID results. The point estimates show a positive relationship between de-reservation and employment, output, capital and wages, and a negative relationship between de-reservation and labor productivity. The results are statistically significant for both employment and output. In the data, the average change in the fraction of de-reserved employment was 0.076. Thus, the point estimate from panel A, at 0.785 , suggests a 6 percent increase in district-level employment.

We note that the coefficient on neighboring-district de-reservation is negative for all variables and significant for both output and productivity. These results are consistent with the migration of workers and economic activity toward neighboring districts that experienced higher levels of de-reservation. Additional specifications interact a dummy for pro-employer with the fraction de-reserved. While our main results are unaffected, we find that the employment creation associated with the SSI reform is driven by labor expansion in states that were not pro-employer. 
Table 9-Checking for Spillovers into Unorganized Manufacturing: Long Differences, 2000-2005

\begin{tabular}{lcccc}
\hline \hline & $\Delta \log ($ labor $)$ & $\Delta \log ($ output $)$ & $\Delta \log ($ capital $)$ & $\Delta \log (\mathrm{Q} / \mathrm{L})$ \\
\hline$\Delta$ organized sector & -0.608 & 0.505 & -0.183 & 1.113 \\
manufacturing de-reserved & $(0.451)$ & $(0.668)$ & $(0.697)$ & $(0.613)$ \\
Observations & 401 & 401 & 401 & 401 \\
$R^{2}$ & 0.007 & 0.002 & 0.000 & 0.013 \\
\hline
\end{tabular}

Notes: Results from district-level regressions of changes in dependent variables (shown in column headings) for the unorganized manufacturing sector from 2000-2005 on change in fraction of organized (ASI) sector district employment in 2000 that was subsequently associated with product de-reservation. Q/L indicates labor productivity (real output divided by number of employees). Regressions are weighted by initial labor shares and use all districts that, after applying weights, have at least ten establishments in each year. Errors are heteroskedasticity-robust.

These additional results suggest that the SSI reservation policy was more binding in pro-worker states.

To summarize, the removal of SSI reservations increased formal sector employment. At the same time, it is possible that the SSI policy reforms affected unorganized, or informal, manufacturing as well. One possibility is that the reforms drove formal sector workers into informal sector jobs, which typically pay lower wages and provide fewer benefits. While panel data do not exist for the unorganized sector, we used two rounds of the National Sample Survey Office's Unorganized Manufacturing Enterprises Survey-from 2000 and 2005-to conduct a district-level analysis. Table 9 shows the results of regressing the changes in unorganized sector employment, output, capital, and labor productivity, at the district level, on the change in de-reservation in the formal sector. We do not include wage as an outcome variable, as many unorganized establishments rely on unpaid family members.

There is no statistically significant association between the fraction of de-reservation and district-level employment in unorganized manufacturing. If anything, the negative coefficient on unorganized employment in Table 9 and the positive coefficient in Table 8 suggest that de-reservation may have been associated with a shift away from the unorganized sector toward organized sector employment.

\section{Additional Robustness Checks}

In this section, we document a number of additional checks to test the robustness of the results in various ways.

Product Switching-The positive coefficients on entrants may reflect the fact that establishments moving into these product spaces are a selected sample. Entrants focusing on core competencies may have been expected to grow even in the absence of the de-reservation. To investigate this possibility, we include a dummy variable that equals one when an establishment changes its main product, regardless of whether the product is reserved, is de-reserved, or was never reserved. Table 10 shows that establishments that switch products do, in fact, appear to grow, suggesting selection into switching. Nonetheless, the effects of the de-reservation remain robust in magnitude and significance. 
Table 10-Impact of De-Reservation on Establishment-Level Outcomes, Controlling For Product Switching

\begin{tabular}{|c|c|c|c|c|c|}
\hline & $\log ($ labor $)$ & $\log ($ output $)$ & $\log ($ capital $)$ & $\log ($ wage $)$ & $\log (\mathrm{Q} / \mathrm{L})$ \\
\hline \multicolumn{6}{|l|}{ Panel A. Aggregate results } \\
\hline$t \geq$ year de-reserved & $\begin{array}{r}-0.00568 \\
(0.00861)\end{array}$ & $\begin{array}{c}0.0213 \\
(0.0120)\end{array}$ & $\begin{array}{c}0.00579 \\
(0.00992)\end{array}$ & $\begin{array}{c}0.0127 \\
(0.00485)\end{array}$ & $\begin{array}{c}0.0149 \\
(0.00974)\end{array}$ \\
\hline Switch & $\begin{array}{c}0.0608 \\
(0.00306)\end{array}$ & $\begin{array}{c}0.0860 \\
(0.00459)\end{array}$ & $\begin{array}{c}0.0252 \\
(0.00371)\end{array}$ & $\begin{array}{c}0.0189 \\
(0.00196)\end{array}$ & $\begin{array}{c}0.0426 \\
(0.00389)\end{array}$ \\
\hline Establishment fixed effects & Yes & Yes & Yes & Yes & Yes \\
\hline Year fixed effects & Yes & Yes & Yes & Yes & Yes \\
\hline Observations & 298,984 & 294,157 & 292,998 & 296,575 & 294,157 \\
\hline Establishments & 130,397 & 128,033 & 127,822 & 128,986 & 128,033 \\
\hline$R^{2}$ & 0.008 & 0.013 & 0.003 & 0.026 & 0.008 \\
\hline \multicolumn{6}{|l|}{ Panel B. Incumbents versus entrants } \\
\hline Incumbent $\times t \geq$ year de-reserved & $\begin{array}{c}-0.0205 \\
(0.00946)\end{array}$ & $\begin{array}{c}-0.0180 \\
(0.0127)\end{array}$ & $\begin{array}{c}-0.00974 \\
(0.0106)\end{array}$ & $\begin{array}{c}0.00181 \\
(0.00507)\end{array}$ & $\begin{array}{c}-0.0157 \\
(0.0102)\end{array}$ \\
\hline Entrant $\times t \geq$ year de-reserved & $\begin{array}{c}0.0737 \\
(0.0194)\end{array}$ & $\begin{array}{c}0.231 \\
(0.0324)\end{array}$ & $\begin{array}{c}0.0893 \\
(0.0254)\end{array}$ & $\begin{array}{c}0.0708 \\
(0.0138)\end{array}$ & $\begin{array}{c}0.178 \\
(0.0274)\end{array}$ \\
\hline Switch & $\begin{array}{c}0.0602 \\
(0.00306)\end{array}$ & $\begin{array}{c}0.0846 \\
(0.00459)\end{array}$ & $\begin{array}{c}0.0247 \\
(0.00371)\end{array}$ & $\begin{array}{c}0.0185 \\
(0.00197)\end{array}$ & $\begin{array}{c}0.0416 \\
(0.00389)\end{array}$ \\
\hline Establishment fixed effects & Yes & Yes & Yes & Yes & Yes \\
\hline Year fixed effects & Yes & Yes & Yes & Yes & Yes \\
\hline Observations & 298,984 & 294,157 & 292,998 & 296,575 & 294,157 \\
\hline Establishments & 130,397 & 128,033 & 127,822 & 128,986 & 128,033 \\
\hline$R^{2}$ & 0.008 & 0.014 & 0.003 & 0.026 & 0.009 \\
\hline
\end{tabular}

Notes: Results from establishment-level regressions. Dependent variables are shown in column headings. " $t \geq$ year de-reserved" is a dummy variable that takes a value of 1 if the product associated with the establishment is removed from the list of reserved products. Incumbent indicates that the establishment previously made the product when it had reserved status. Entrant indicates that the establishment only made the product after it had been de-reserved. Switch is a dummy that takes a value of 1 when an establishment changes the main product it makes. $\mathrm{Q} / \mathrm{L}$ indicates labor productivity (real output divided by number of employees). Errors are clustered at the establishment level.

Establishment-Specific Time Trends.-We might be concerned that our differential results for entrants and incumbents suggest that de-reservation attracted entrants who were already growing quickly. Thus, we conducted a robustness check to control for establishment-specific time trends. For each outcome of interest, we first conducted a separate regression, for each establishment, of the outcome on a time trend. We used the coefficient on the time trend to generate predicted values for that outcome of interest and for that establishment. We then combined all of the establishment-specific predicted values for a particular outcome of interest into one variable (for example, $\ln (\widehat{\text { labor }})$ and included this variable as a control in the relevant regression (i.e., the regression for that outcome of interest; for example we included $\ln (\widehat{\text { labor }})$ in the labor regressions, $\ln (\widehat{\text { output }})$ in the output regressions, and so forth). When including the predicted variables as independent variables, we bootstrapped standard errors. Results, shown in online Appendix Table C.1, are very close to the baseline results. ${ }^{23}$

\footnotetext{
${ }^{23}$ However, the number of observations is lower than in the baseline results as we can only include an establishment-specific trend for establishments observed at least twice.
} 
Product-Level Time Trends.-Another concern is that the timing of the de-reservation policy coincides with pre-de-reservation product-specific growth rates. We address this concern in earlier sections by including an event-time trend that varies by years relative to de-reservation, and by performing explicit checks for product-level pretrends. An alternative approach is to include separate time trends for every product. We implement this robustness check in the same way as the establishment-level trends above. For each product, we regress each outcome of interest on a time trend, using all establishments that produce that product. We then include the predicted values of the relevant outcome variable as a control in the establishment-level regressions, bootstrapping standard errors to account for prediction error. Results, shown in online Appendix Table C.2, are again very close to the baseline results.

Additional Controls. - We also test the robustness of our results to controlling for a variety of additional characteristics: industry-by-year dummies (industry dummies at the three-digit level); initial location dummies interacted with year dummies; initial age (dummies for five age groups) interacted with year dummies; the initial ratio of production to total workers (dummies for ten deciles) interacted with year dummies; and the initial ratio of capital to number of workers (dummies for ten deciles) interacted with year dummies. Results are reported in online Appendix Table C.3 and are similar to baseline findings.

Industry-Level Results. - This paper emphasizes establishment-, product-, and district-level measures to evaluate the impact of de-reservation. Conducting the analysis at the industry level is likely to be less accurate because only a handful of products were typically reserved in each industry. Nonetheless, to check for additional robustness to this level of analysis, we created an aggregate industry level measure of exposure to de-reservation at time $t$. Use of the sampling multipliers means that smaller establishments, which frequently make SSI products, are given greater weight in these regressions than they are in the establishment-level results.

We use the sampling weights provided by the ASI to create a representative sample of establishments at the industry level. We measure industries at the four-digit level; in the ASI there are 124 such industries. Assigning a single date for de-reservation at the industry level is problematic because most industries have multiple de-reserved products, many of which have different dates of de-reservation. Instead we adopt an approach similar to that used in the district-level regressions, following Topalova (2010). We calculate the exposure of each industry $j$ to de-reservation at time $t$ as the sum over all products of revenue associated with each product $p$ in industry $j$ in 2000, multiplied by a dummy variable indicating whether the product was de-reserved, and divided by total product revenues in that industry in 2000:

$$
\text { FrDeres }_{j t}=\frac{\sum_{p}\left(\text { Revenue } 2000_{j p} \times \text { Deres }_{p t}\right)}{\text { Total Product Revenue } 2000_{j}} .
$$

Our left-hand-side variables are contemporaneous measures of aggregate labor, output, capital, average wage (calculated as aggregate wage payments divided by aggregate labor), and aggregate number of establishments at the industry level. We 
then estimate the effects of exposure to de-reservation on each outcome of interest $y$ as follows:

$$
y_{j t}=\beta \text { FrDeres }_{j t}+\alpha_{j}+\alpha_{t}+\mu_{j t}
$$

We also include a long-difference specification, which uses the change in the fraction de-reserved, and the changes in the outcomes of interest, between 2000 and 2007:

$$
\Delta y_{j}=\beta \Delta \text { FrDeres }_{j}+\mu_{j}
$$

The results, reported in online Appendix Table C.4, demonstrate that de-reservation is associated with a significant increase in total employment. The results in panel A from the annual fixed effect regressions indicate that if an industry were to go from fully reserved to fully de-reserved, employment would increase by more than 25 percent. The average fraction of industry-level employment de-reserved between 2000 and 2007 was 20 percent. The point estimate from panel B, at 0.565 , therefore represents an 11 percent increase in employment on average. Although the coefficient on output is also positive, it is not statistically different from zero, and the percentage increase is less than the percentage increase in employment. These findings are consistent with our district-level results, which also show that de-reservation is associated with increases in employment and output.

\section{SSI Policy and the Size-Age-Growth Relationship}

Our results show that eliminating product reservation for small establishments in India boosted aggregate employment growth. The literature on the relationship between establishment size, age, and growth has typically focused not on a specific policy change, but on the reduced-form relationship between these variables at a snapshot in time. A number of papers in this vein suggest that small firms grow faster, both in developed and developing countries (see, among others, Evans 1987a, b; Gunning and Mengistae 2001; Ayyagari, Demirguc-Kunt, and Maksimovic 2011; Neumark, Wall, and Zhang 2011). ${ }^{24}$ Recently, however, Haltiwanger, Jarmin, and Miranda (2013) demonstrate that in the United States, after controlling for firm age, and accounting for regression to the mean and exit, small firms do not grow faster than large firms.

In this section we present the reduced-form relationship between establishment size, age, and employment growth for manufacturing firms in India, making corrections as in Haltiwanger, Jarmin, and Miranda (2013) for regression to the mean effects and for the fact that small establishments are more likely to exit than large establishments. We address the potential for regression to the mean by measuring size as average size in periods $t$ and $t^{\prime}$ :

$$
\bar{S}(t)=0.5\left[S(t)+S\left(t^{\prime}\right)\right]
$$

\footnotetext{
${ }^{24} \mathrm{Li}$ and Rama (2015) survey much of the literature on firm dynamics in developing countries, and conclude that including micro-enterprises is critical for correctly identifying patterns of job creation and productivity growth.
} 
Employment growth is measured as size in period $t^{\prime}$ minus size in period $t$, divided by average size and by the gap between the two periods:

$$
\overline{\operatorname{Growth}}(t)=\frac{S\left(t^{\prime}\right)-S(t)}{\bar{S}(t)\left[t^{\prime}-t\right]} .
$$

Another challenge in estimating the relationship between size and growth arises because of sample selection. Small establishments tend to have higher failure rates than large establishments. These higher failure rates mean that if only continuing establishments are included in estimates of the size-growth relationship, then the estimated growth rate of small establishments is likely to be biased upward. Examining only continuing establishments also fails to account for growth due to entry, which may bias the growth rate of small establishments downward. To overcome these challenges, we replicate the Haltiwanger, Jarmin, and Miranda (2013) measure of growth, which allows for both entry and exit.

To exclude any potential effects of the SSI policy, we exclude all establishments that were affected by the SSI policies, either as incumbents or as entrants into reserved products. The exercise provides a robustness check on the previous section, ties our results to the existing literature, and casts light on the long-run relationship between employment growth and establishment size and age.

The results are summarized in Figure 5. The figure shows projected employment growth rates for each size and age class across Indian establishments that were never affected by small-scale reservation. Each bar represents projected growth by size and age class, controlling for a number of other characteristics.

The results are remarkably consistent with the findings of Haltiwanger, Jarmin, and Miranda (2013) for the United States, and with our findings of the impact of dismantling the SSI reservation policy. Taking into account the high failure rate of smaller establishments, the establishments with the fastest labor growth are either young or big. Average employment growth is positive and high for nearly all establishments with at least 500 employees. Employment growth is also positive for nearly all size classes of establishments between 1 and 2 years of age. Controlling for age, the largest establishments experienced the highest employment growth. Controlling for size, the youngest establishments also experienced the highest employment growth.

\section{Concluding Comments}

In this paper, we use the elimination of a policy that promoted small and medium establishments in India to answer the following question: which kinds of establishments create more employment? For the past 60 years, India has promoted small-scale industry (SSI) by reserving production of some goods for smaller establishments. During the sample period, one in four establishments in the Annual Survey of Industries was covered by this policy. ${ }^{25}$ The stated goal of small-scale

\footnotetext{
${ }^{25}$ Since large establishments are over-represented in the sample, and the reservation policy was targeted at small establishments, it is likely that an even greater share of the overall population of formal establishments was covered by the policy.
} 




Figure 5. Projected Employment Growth by Size And Age

Notes: Projected establishment employment growth rates for each size and age class. Size is measured as average employment between the previous period observed and the current period. Employment growth is measured as described in the text. Growth measure accounts for both entry and exit.

reservation was to promote employment growth and income redistribution, but some commentators have argued that the policy constrained growth. We use the elimination of the SSI reservation policy between 1997 and 2007 as an exogenous shock to understand size and employment linkages over time.

Our results suggest that eliminating incentives for small establishments boosted aggregate employment growth. India eliminated all but a handful of product restrictions protecting small and medium establishments from competition over a short horizon between 1997 and 2007. This period was characterized by few other reforms, as most of the trade liberalization and dismantling of the License Raj had been done in previous decades. The elimination of small-scale reservation over a short horizon allows us to measure the importance of size in employment promotion.

We find that districts that were more exposed to elimination of the reservations for SMEs experienced higher employment growth between 2000 and 2007. The magnitude of the effect is large: between 2000 and 2007 a district facing the average amount of de-reservation would have experienced a 6 percent increase in overall employment.

To explore the mechanisms that led to net employment growth, we examine the effects of the de-reservation policy at the establishment level. Reserving products for SMEs was intended to protect employment in small establishments. We find that eliminating this policy decreased employment among smaller, older establishments. Critics 
of the policy suggested that product reservation was holding back the growth of larger establishments. Consistent with their claims, we find that the entry and expansion of output, employment, and investment were driven by new entrants to the previously reserved product space as well as establishments that were previously constrained from expanding their existing stock of fixed assets. We also document increased investment in plant and machinery among these previously constrained incumbents. Our findings can be interpreted through the lens of the heterogeneous firms literature (Melitz 2003); as de-reservation increases competition in a product market, large establishments increase their market shares at the expense of small establishments.

How well did the reservation policy achieve its goals? While small-scale reservation may have protected employment in certain small establishments, it did so at the expense of employment elsewhere. With respect to the goal of income enhancement, our results show that eliminating reservation policies for smaller establishments increased average wages. However, it is not clear whether this effect is due to entrants paying higher wages to existing workers, or to a shift toward a higher skilled workforce. Our analysis suggests that the removal of small-scale reservations increased overall employment by encouraging the growth of younger, larger establishments - those that are most likely to pay higher wages, create more investment, be more productive, and generate growth in employment.

\section{ApPendix A}

Table A1-Evolution of SSi Ceiling on Investment in Plant and Machinery

\begin{tabular}{ll}
\hline \hline & \\
\hline 1950 & $\begin{array}{l}\text { Rs 5 lakhs in fixed assets and employment less than 50/100 workers with/without } \\
\text { power }\end{array}$ \\
1960 & $\begin{array}{l}\text { Rs 5 lakhs in fixed assets } \\
1966\end{array}$ \\
1975 & Rs 7.5 lakhs in plant and machinery \\
1980 & Rs 10 lakhs \\
1985 & Rs 20 lakhs \\
1991 & Rs 60 lakhs \\
1997 & Rs 300 lakhs \\
1999 & Rs 100 lakhs \\
2006 & Rs 500 lakhs \\
\hline
\end{tabular}

Note: 1 lakh $=100,000(100$ lakhs $=$ Rs 10 million $)$.

Sources: Mohan (2002), Table 6.1; Micro, Small and Medium Enterprises Act (2006).

\section{REFERENCES}

Aghion, Philippe, Robin Burgess, Stephen J. Redding, and Fabrizio Zilibotti. 2008. "The Unequal Effects of Liberalization: Evidence from Dismantling the License Raj in India." American Economic Review 98 (4): 1397-412.

Alfaro, Laura, and Anusha Chari. 2009. "India Transformed? Insights from the Firm Level 19882005." India Policy Forum 6.

Alfaro, Laura, and Anusha Chari. 2014. "Deregulation, Misallocation, and Size: Evidence from India." Journal of Law and Economics 57 (4): 897-936.

Ayyagari, Meghana, Asli Demirguc-Kunt, and Vojislav Maksimovic. 2011. "Small vs. Young Firms across the World: Contribution to Employment, Job Creation, and Growth." World Bank Policy Research Working Paper 5631. 
- Banerjee, Abhijit Vinayak. 2006. "The Paradox of Indian Growth: A Comment on Kochhar et al." Journal of Monetary Economics 53 (5): 1021-26.

Banerjee, Abhijit V., and Esther Duflo. 2014. "Do Firms Want to Borrow More? Testing Credit Constraints Using a Directed Lending Program.” Review of Economic Studies 81 (2): 572-607.

-Besley, Timothy, and Robin Burgess. 2004. "Can Labor Regulation Hinder Economic Performance? Evidence from India.” Quarterly Journal of Economics 119 (1): 91-134.

-Bigsten, Arne, and Mulu Gebreeyesus. 2007. "The Small, the Young, and the Productive: Determinants of Manufacturing Firm Growth in Ethiopia." Economic Development and Cultural Change 55 (4): 813-40.

Chari, Anusha, and Nandini Gupta. 2008. "Incumbents and Protectionism: The Political Economy of Foreign Entry Liberalization.” Journal of Financial Economics 88 (3): 633-56.

Chetty, Raj, Adam Looney, and Kory Kroft. 2009. "Salience and Taxation: Theory and Evidence." American Economic Review 99 (4): 1145-77.

Das, Sanghamitra. 1995. "Size, Age and Firm Growth in an Infant Industry: The Computer Hardware Industry in India." International Journal of Industrial Organization 13 (1): 111-26.

De Loecker, Jan, Pinelopi K. Goldberg, Amit K. Khandelwal, and Nina Pavcnik. 2016. "Prices, Markups, and Trade Reform." Econometrica 84 (3): 445-510.

Eckel, Carsten, and J. Peter Neary. 2010. "Multi-product Firms and Flexible Manufacturing in the Global Economy." Review of Economic Studies 77 (1): 188-217.

Evans, David S. 1987a. "Tests of Alternative Theories of Firm Growth." Journal of Political Economy 95 (4): 657-74.

Evans, David S. 1987b. “The Relationship between Firm Growth, Size, and Age: Estimates for 100 Manufacturing Industries." Journal of Industrial Economics 35 (4): 567-81.

Garcia-Santana, Manuel, and Josep Pijoan-Mas. 2014. "The Reservation Laws in India and the Misallocation of Production Factors." Journal of Monetary Economics 66: 193-209.

Garicano, Luis, Claire LeLarge, and John Van Reenen. 2016. "Firm Size Distortions and the Productivity Distribution: Evidence from France.” American Economic Review 106 (11): 3439-79.

- Goldberg, Pinelopi Koujianou, Amit Kumar Khandelwal, Nina Pavcnik, and Petia Topalova. 2010a. "Imported Intermediate Inputs and Domestic Product Growth: Evidence from India." Quarterly Journal of Economics 125 (4): 1727-67.

Goldberg, Pinelopi K., Amit K. Khandelwal, Nina Pavcnik, and Petia Topalova. 2010b. "Multiproduct Firms and Product Turnover in the Developing World: Evidence from India." Review of Economics and Statistics 92 (4): 1042-49.

Government of India Ministry of Statistics and Programme Implementation. 1998-2010. Annual Survey of Industries (ASI). New Delhi: Ministry of Statistics and Programme Implementation.

Gunning, Jan Willem, and Taye Mengistae. 2001. "Determinants of African Manufacturing Investment: The Microeconomic Evidence.” Journal of African Economies 10 (AERC Supplement 2): 48-80.

Gupta, Nandini. 2005. "Partial Privatization and Firm Performance." Journal of Finance 60 (2): 9871015.

Hall, Bronwyn H. 1987. "The Relationship between Firm Size and Firm Growth in the U.S. Manufacturing Sector." Journal of Industrial Economics 35 (4): 583-606.

-Haltiwanger, John, Ron S. Jarmin, and Javier Miranda. 2013. "Who Creates Jobs? Small versus Large versus Young." Review of Economics and Statistics 95 (2): 347-61.

Hsieh, Chang-Tai, and Benjamin A. Olken. 2014. "The Missing 'Missing Middle.'” Journal of Economic Perspectives 28 (3): 89-108.

Hussain, Abid. 1997. Report of the Expert Committee on Small Enterprises. New Delhi: Department of Small Scale Industries and Business Enterprises.

La Porta, Rafael, and Andrei Shleifer. 2008. "The Unofficial Economy and Economic Development." Brookings Papers on Economic Activity (Fall): 275-352.

La Porta, Rafael, and Andrei Shliefer. 2014. "Informality and Development." Journal of Economic Perspectives 28 (3): 109-26.

Li, Yue, and Martín Rama. 2015. "Firm Dynamics, Productivity Growth, and Job Creation in Developing Countries: The Role of Micro- and Small Enterprises.” World Bank Research Observer 30 (1): 3-38.

Martin, Leslie A., Shanthi Nataraj, and Ann E. Harrison. 2017. "In with the Big, Out with the Small: Removing Small-Scale Reservations in India: Dataset." American Economic Review. https://doi. org/10.1257/aer.20141335.

McCaig, Brian, and Nina Pavcnik. 2014. "Export Markets and Labor Allocation in a Low-income Country." National Bureau of Economic Research Working Paper 20455.

McCaig, Brian, and Nina Pavcnik. 2015. "Informal Employment in a Growing and Globalizing Low-Income Country.” American Economic Review 105 (5): 545-50. 
Mead, Donald C., and Carl Liedholm. 1998. "The Dynamics of Micro and Small Enterprises in Developing Countries." World Development 26 (1): 61-74.

Melitz, Marc J. 2003. "The Impact of Trade on Intra-Industry Reallocations and Aggregate Industry Productivity." Econometrica 71 (6): 1695-725.

Mohanan, P. C., and Anil Chopra. 2012. "Problems and Prospects in the Use of ASI Data: A Study on ASI Panel Data.” Journal of Industrial Statistics 1 (1): 32-39.

Mohan, Rakesh. 2002. "Small-Scale Industry Policy in India: A Critical Evaluation.” In Economic Policy Reforms and the Indian Economy, edited by Anne O. Krueger, 213-302. Chicago: University of Chicago Press.

Nataraj, Shanthi. 2011. "The Impact of Trade Liberalization on Productivity: Evidence from India's Formal and Informal Manufacturing Sectors.” Journal of International Economics 85 (2): 292-301.

National Sample Survey Office. 2000-2001, 2005-2006. Unorganized Manufacturing Enterprises Survey Rounds 56 and 62. New Delhi: Ministry of Statistics and Programme Implementation and National Sample Survey Office.

Neumark, David, Brandon Wall, and Junfu Zhang. 2011. "Do Small Businesses Create More Jobs? New Evidence for the United States from the National Establishment Time Series." Review of Economics and Statistics 93 (1): 16-29.

Panagariya, Arvind. 2008. India: The Emerging Giant. Oxford: Oxford University Press.

Shanmugam, K. R., and Saumitra N. Bhaduri. 2002. "Size, Age and Firm Growth in the Indian Manufacturing Sector." Applied Economics Letters 9 (9): 607-13.

-Sleuwaegen, Leo, and Micheline Goedhuys. 2002. "Growth of Firms in Developing Countries, Evidence from Cote D’Ivoire.” Journal of Development Economics 68 (1): 117-35.

Sutton, John. 1997. “Gibrat's Legacy.” Journal of Economic Literature 35 (1): 40-59.

Topalova, Petia. 2010. "Factor Immobility and Regional Impacts of Trade Liberalization: Evidence on Poverty from India." American Economic Journal: Applied Economics 2 (4): 1-41.

Tybout, James R. 2000. "Manufacturing Firms in Developing Countries: How Well Do They Do, and Why?" Journal of Economic Literature 38 (1): 11-44.

Tybout, James. 2014. "The Missing Middle: Correspondence." Journal of Economic Perspectives 28 (4): 235-36.

- Van Biesebroeck, Johannes. 2005. "Firm Size Matters: Growth and Productivity Growth in African Manufacturing." Economic Development and Cultural Change 53 (3): 545-83. 